\title{
LA VIOLENCIA Y LOS CAMBIOS SOCIO-CULTURALES \\ EN LAS AREAS RURALES COLOMBIANAS12
}

Violence and socio-cultural changes in colombian rural areas

TORRES RESTREPO, Camilo ${ }^{3}$

\begin{abstract}
Resumen: Este estudio clásico demarca la situación de la sociología en Colombia entre los años 50 y 60, buscando definir la distinción entre lo normativo y lo positivo. El autor, sociólogo e sacerdote católico, entiende que la sociología colombiana ha conocido influencias directas da las sociologías norteamericanas y europeas, pero presenta sus propias características que son ubicadas en el fenómeno de la violencia. Para él, la violencia en Colombia no es un aspecto puntual, estando presente desde siempre en su movimiento histórico. Aclara el autor que no es posible hacer una sociología colombiana aparte de la sociología universal; sin embargo, es necesario hacer sociología colombiana en dos sentidos: 1을 Aplicando la teoría y los métodos sociológicos generales a nuestra realidad concreta y específica. Y $2^{\circ}$ Contribuyendo a esta teoría y métodos con el análisis de las situaciones nuevas, que la realidad de este país pueda sugerir. El artículo debe ser leído como ejemplo para el entendimiento de la implicación de los sociólogos colombianos con las poblaciones campesinas mezclando acción teórica e positiva al lado de la acción normativa.
\end{abstract}

Palabras-clave: Sociología. Violencia. Cambio social. Campesinos.

Abstract: This classic study demarcates the situation of sociology in Colombia between the 1950s and 1960s, seeking to define the distinction between the normative and the positive. The author, a sociologist and a Catholic priest, believes that Colombian sociology has been directly influenced by North American and European sociologies, but it has its own characteristics which are reflected in the phenomenon of violence. For him, violence in Colombia is not a limited aspect, and it is part of its historical movement. The author clarifies that it is not possible to make a Colombian sociology apart from the universal sociology. However, it is necessary to make a Colombian sociology in two ways: 1) applying the theory and the general sociological methods to our concrete and specific reality; 2) contributing to this theory and methods with the analysis of the new situations produced by this reality. The article should be understood as an example for the understanding of Colombian sociologists involvement with the peasant populations, mixing theoretical and positive action alongside normative action.

Keywords: Sociology. Violence. Social change. Peasants.

\footnotetext{
1 Texto publicado no Primer Congreso Nacional de Sociología pela Asociación Colombiana de Sociología. Editorial Iqueima: Bogotá, 1963,

2 Texto selecionado para este dossiê da REALIS.

3 Religioso progressista ligado à teologia da libertação. Fundador e professor do primeiro curso da Sociologia na Colômbia. Universidad Nacional de Colombia.
} 


\section{Introducción para los profanos}

La ciencia, como todo elemento humano, es ambivalente. Es un instrumento de comunicación más profundo y más sólido con aquellos que están «Iniciados”, pero con aquellos que no lo están, ya sea por cultivar otras disciplinas o por no tener una formación científica, puede ser un instrumento de separación, de malos entendidos y por lo tanto de conflicto.

El autor del presente estudio es un sacerdote que a la vez es sociólogo; sería interesante hacer una amplia demostración sobre las relaciones que tienen estas dos actividades como, en general, mostrar las diferencias y las aplicaciones de lo sagrado y lo profano.

Para enfocar este problema deberíamos plantear en toda su extensión las aplicaciones psicológicas, sociológicas e históricas de la Encarnación de Dios con todas sus consecuencias. Sin embargo, estas consideraciones se salen del objeto principal de la presente introducción.

Para poder ejercer las funciones de puente entre los colegas sacerdotes y los colegas sociólogos, creo que basta con hacer unas consideraciones rápidas sobre la distinción entre lo normativo y lo positivo.

La ciencia positiva es básicamente inductiva; parte de la observación empírica para llegar a generalizaciones de primer grado de abstracción; es decir a generalizaciones que nos den una certidumbre física, una incertidumbre que se mantiene aceptando cualquier hecho en contra para modificarse. No se aspira a la certidumbre metafísica que está en el tercer grado de abstracción y se basa en la esencia inmutable de los seres. Las ciencias normativas como la moral, la política, el derecho, se tienen que basar en alguna certidumbre metafísica. Las ciencias positivas constatan los hechos, hacen generalizaciones lógicas y están sometidas a las verificaciones empíricas para corregir, ampliar y si es el caso abolir las generalizaciones.

El presente estudio pretende ser un trabajo de sociología positiva. Como lo explicaremos más adelante, no está fundamentalmente sustentado por un análisis de campo; toma las experiencias directas de otros y las observaciones no estandarizadas del 
autor para enunciar una serie de hipótesis de trabajo.

Desde el punto de vista metodológico y científico este sistema es incompleto, pero no erróneo. Aunque, como dijimos atrás, la ciencia positiva se tiene que basar fundamentalmente en las observaciones empíricas cuando ellas tienen suficiente desarrollo, como en el caso de la sociología, es necesario relacionar la observación con una teoría general. Por otra parte, para enriquecer la teoría general se requiere lanzar hipótesis que solamente la intuición del científico puede preservar de que (sic) sean gratuitas. En teoría son, por definición (ya que son hipótesis) básicamente gratuitas. Precisamente se plantean para que sean verificadas por la investigación positiva. En otras palabras, los trabajos científicos pueden iniciarse por cualquiera de los extremos: partiendo de generalizaciones, que corren el riesgo de ser gratuitas para llegar a constataciones empíricas; o partir de estas constataciones para llegar a generalizaciones que tienen el carácter de leyes científicas.

No obstante la evolución de la sociología, especialmente en los últimos años, tenemos que reconocer que es una ciencia joven. Como tal, sus conceptos, su terminología, sus métodos y sus leyes no están aún suficientemente estructurados. Algunos sociólogos, principalmente de fines del siglo pasado y principios del presente, optaron por una posición sectaria. Unos defendían la teoría y los planteamientos generales contra las investigaciones empíricas de escasa trascendencia teórica pero de mucha precisión técnica. Los sociólogos europeos, en general, adoptaron esta posición.

Otros, por el contrario (entre los que se contaron muchos sociólogos norteamericanos) se dedicaron a minuciosas investigaciones sobre el terreno atacando las generalizaciones gratuitas.

Se ha dicho que la sociología europea es más interesante que verdadera y que la sociología norteamericana es más verdadera que interesante. Sin embargo, podemos afirmar que hoy en día en términos generales, esta dicotomía ha sido superada, y podemos hablar de una sociología universal.

Actualmente, el método inductivo y el método deductivo (de lo general a lo particular o de lo particular a lo general) son valederos mientras se acepte que son complementarios, que ninguno de los dos es verdaderamente científico si excluye al otro. 
Con todo, el avance de la ciencia es paulatino y exige contribuciones parciales que también deberán ser complementarias.

En el caso de la "sociología colombiana" encontramos una tradición que no podemos clasificar dentro de la sociología positiva. Hasta hace pocos años solamente se podía hablar de filósofos sociales. En los últimos tiempos hemos visto surgir la sociología positiva en nuestro país. Por inspiración norteamericana al principio, complementada posteriormente con influencias europeas. El aspecto empírico de la sociología empieza a prevalecer entre nosotros con una orientación tal que se puede correr el peligro de consagrarse únicamente al estudio de este campo descuidando las generalizaciones.

No es posible hacer una sociología colombiana aparte de la sociología universal. Sin embargo, es necesario hacer sociología colombiana en dos sentidos: 1o aplicando la teoría y los métodos sociológicos generales a nuestra realidad concreta y específica. Y $2^{\mathrm{o}}$ contribuyendo a esta teoría y métodos con el análisis de las situaciones nuevas, que nuestra realidad pueda sugerir. Esta sociología colombiana se vería frustrada en su estructuración tanto si faltara la investigación empírica como si prescindiera de la generalización teórica. El presente estudio pretende ser una contribución a este último aspecto.

Aunque como sacerdote el autor debe desaprobar los hechos sociales que estén en oposición a la moral cristiana, como sociólogo no se puede permitir la emisión de juicios de valor so pena de caer en el error metodológico de mezclar las ciencias positivas con las ciencias normativas. Por eso, no es de extrañar que se describa un fenómeno como el de la "violencia" - que, en términos generales, no puede justificarse desde el punto de vista moral - como un factor de cambio social importante, sin pronunciarse sobre la bondad o la maldad de ese cambio y sobre la moralidad de sus consecuencias. Al decir "importante" no se quiere decir "constructivo". Ese vocablo se utiliza solamente en el plano de los fenómenos positivos que si por causa de la violencia han sido profundamente transformadores, tienen una importancia sociológica indiscutible.

Las observaciones anteriores podrían situar al lector que no esté familiarizado con los análisis positivos de las realidades sociales, en el terreno propicio para valorar los planteamientos que se hacen en este trabajo dentro de las limitaciones de la ciencia empírica que no puede pretender generalizaciones normativas. 


\section{Alcance del análisis}

Para poder precisar la magnitud de un cambio, es necesario determinar bien claramente tres aspectos:

a) La situación antes del cambio.

b) Los factores que influyen y la manera en que influyen en el cambio.

c) La situación posterior a la acción de dichos factores.

Sin embargo, es necesario anotar que en un cambio sociocultural los anteriores puntos de referencia son mucho menos precisos que en el caso de un cambio físico. Las variables sociales poseen una dinámica constante y por eso es imposible considerar situaciones estables dentro del cambio social.

Con todo, la sociedad rural colombiana antes de pasar por el fenómeno de la "violencia" 41 era una sociedad relativamente estática, como trataremos de describir a continuación. Esto facilita en parte el establecimiento del cambio ocurrido. A pesar de ello, es necesario limitar el fenómeno de cambio a algunas variables, ya que, por su complejidad, no podría describirse nunca en forma exhaustiva. ${ }^{5}$

Muchas de las variables que consideraremos no son de ninguna manera exclusivas de la sociedad colombiana. En muchos textos de sociología las encontramos como criterios determinantes de cualquier sociedad rural. Las hemos escogido aquí por considerar que han sido afectadas especialmente por el fenómeno de la violencia.

El presente análisis se refiere casi exclusivamente a la descripción hecha por monseñor Germán Guzmán en el primer tomo del libro La violencia en Colombia y a los trabajos efectuados en relación a la sociedad rural colombiana, antes de haber sufrido el

\footnotetext{
${ }^{4} \mathrm{Al}$ fenómeno de la violencia en Colombia podemos definirlo como un tipo de conflicto social que se manifiesta por la acción armada de grupos, especialmente en vecindarios campesinos, generalizada geográficamente en "Colombia" y de carácter endémico, ya que se ha prolongado por varios años sin solución de continuidad. Para mayor explicación cfr. Germán Guzmán C., Eduardo Umaña Luna, Orlando Fals Borda, La violencia en Colombia, edición monografía sociológica, Facultad de sociología, U.N. Bogotá, 1962, pág. 368.

${ }^{5}$ Es de notar también que en el presente estudio no consideramos sino las áreas que han sido afectadas, en algún momento, por el fenómeno. Sin embargo, de acuerdo con los estudios realizados, especialmente por monseñor Germán Guzmán, casi todas las áreas rurales colombianas (cfr. La violencia en Colombia -estudio de un proceso social - tomo I, Ediciones tercer mundo, Bogotá, 1962) han sido afectadas por la violencia.
} 
impacto de la violencia. ${ }^{6}$

Aquí trataremos de estructurar los datos de los trabajos mencionados dentro de un esquema teórico adaptado a la descripción del cambio ocasionado por la violencia. $\mathrm{Su}$ valor objetivo dependerá de la objetividad de dichos estudios y muchas de las afirmaciones no podrán tener un sentido más amplio que el de ser simples hipótesis de trabajo que deberán ser sometidas a ulteriores investigaciones sobre el terreno para llegar a ser debidamente comprobadas, como lo explicamos ampliamente en la Introducción.

Con estas observaciones podemos entrar de lleno al análisis del cambio socio-cultural, considerando:

1ํㅡa situación de las variables seleccionadas, antes de la violencia.

$2^{\circ}$ La forma en que fueron afectadas esas variables por el fenómeno de la violencia.

3ํㅡㄹ resultado final.

Las variables las clasificaremos en tres grupos:

$1^{\text {o }}$ Aquellas que son comunes a toda sociedad rural.

2ํA Aquellas que son propias de las sociedades rurales de los países subdesarrollados.

3ํA Aquellas que son características de la sociedad rural colombiana.

Naturalmente que la división anterior no deja de ser artificial. La tomamos para ordenar mejor el análisis pero trataremos de hacer las aplicaciones concretas a Colombia, aun en las dos primeras categorías de variables.

\section{Variables consideradas}

\section{$1^{\circ}$ variables comunes a toda sociedad rural}

a) Falta de división del trabajo, de especialización y escasez de roles.

\footnotetext{
${ }^{6}$ Gustavo Pérez, El campesino colombiano, un problema de estructura, Centro de investigaciones sociales, Bogotá, 1962; Orlando Fals Borda, Campesinos de los Andes, Editorial Iquelma, Bogotá, 1961; El hombre y la tierra en Boyacá, Editorial Antares, Bogotá, 1956.
} 
b) Aislamiento social.

c) Importancia de los vecindarios en la vida social.

d) individualismo.

e) Conflicto con el extra-grupo.

f) sentimiento de inferioridad.

$2^{\circ}$ variables propias de las sociedades rurales de países subdesarrollados

a) Ausencia de movilidad vertical ascendente.

b) Agresividad latente.

$3^{o}$ variables características de la sociedad rural colombiana

a) Sectarismo político.

b) Falta de conciencia de clase.

c) Respeto a la propiedad privada.

\section{Cambios socio-culturales ocurridos en cada una de las variables consideradas}

$1^{\circ}$ Variables comunes a toda sociedad rural

a) Falta de división del trabajo, de especialización y escasez de roles

La actividad agropecuaria del cultivo de la tierra y del ganado es prácticamente la exclusiva del campesino colombiano. En general, toda otra ocupación está condicionada por ésta: el mercado, la actividad religiosa, familiar, etc.

La violencia plantea al campesino nuevas necesidades y con ellas la imposición de una división del trabajo y de una especialización. Para los grupos activos además de las necesidades requeridas en toda acción bélica, surgen aquellas específicas de la guerra de guerrillas, tales como las de espionaje, comunicaciones clandestinas, abastecimiento, asistencia social, relaciones públicas, etc. ${ }^{7}$

${ }^{7}$ Cfr. Guzmán, Umaña, Fals Borda, La violencia en Colombia, monografías sociológicas № 12 - Facultad de 
Respecto de los grupos pasivos, también debemos comprobar la aparición de nuevas necesidades, tales como las de vigilancia, colaboración, tanto entre sí como con los grupos guerrilleros, todas aquellas impuestas en el caso de las migraciones forzadas, etc.

Para cada una de estas necesidades ha sido indispensable destacar elementos de la comunidad rural para que las ejerzan habitualmente, llegando así a un género de especialización que, aunque rudimentario, es importante respecto de las relaciones sociales.

Estas relaciones en la sociedad rural, como consecuencia de la falta de división y especialización del trabajo, son de características más íntimas, frecuentes y personales. Este tipo de relaciones conduce a un tipo de sociedad folk, también descrita por Redfield:

Esta sociedad es pequeña, aislada, iletrada y homogénea, con fuerte sentido de solidaridad. El modo de vida está convencionalizado dentro de un sistema coherente que llamamos 'una cultura'. La conducta es tradicional, espontánea, acrítica y personal. No hay legislación, hábito de experimentación ni reflexión para fines intelectuales. El parentesco, sus relaciones e instituciones son del tipo de categorías empíricas, y el grupo familiar es la unidad de acción. Lo sagrado prevalece sobre lo secular. La economía es de autoconsumo más bien que de mercado. ${ }^{8}$

Todas estas características se aplicaban exactamente a nuestra sociedad rural antes de haber pasado por la violencia.

Dentro de esto tenemos que señalar: la conducta tradicional, espontánea, no crítica y personal como un efecto de la preponderancia de las relaciones secundarias. Ahora bien, la falta de división del trabajo y de especialización lleva a esta preponderancia, ya que la persona que realiza muchas funciones es la base de la interacción social mucho más que la función misma. La falta de especialización hace que no exista una exigencia ni una expectación social respecto del progreso por la instrucción formal.

La solidaridad de grupo es otro efecto de la falta de división del trabajo, si nos referimos a la solidaridad mecánica dentro de la teoría durkheiniana. ${ }^{9}$ Esta

sociología, U.N. Bogotá, 1962, pp. 147 et passim.

${ }^{8}$ Robert Redfield, The Folk Society, the American Journal of sociology, 52 (enero de 1947), p. 293.

${ }^{9}$ Émile Durkheim, De la división du Travail Social, (1902), XXXII. 
solidaridad mecánica produce naturalmente un sistema coherente de vida basado en la tradición y el sentimiento.

Dentro de la teoría de Tönnies nuestra sociedad rural se acerca mucho más a la comunidad (gemeinschaft) que a la sociedad (gesellschaft). Por otro lado, la economía de autoconsumo estimula mucho más las relaciones primarias que secundarias y es una de las causas de la falta de división del trabajo.

Los efectos de estos fenómenos sobre la actitud respecto del cambio social son de una gran importancia. La predominancia de las relaciones primarias sobre las secundarias comienza a desaparecer por la mayor división del trabajo, la mayor especialización y por consiguiente la multiplicación y diversificación de los roles sociales.

En las comunidades afectadas por la violencia, las interacciones sociales comienzan a basarse más en las funciones de las personas que en la persona misma. La solidaridad de grupo comienza a ser más orgánica que mecánica, es decir, más basada en la complementariedad de los roles diversos que en la homogeneidad de éstos. Las relaciones sociales comienzan a basarse más en la razón que en la tradición y el sentimiento. La conducta deja de ser tradicional y espontánea y pasa a ser crítica e impersonal. ${ }^{10}$ La "comunidad" se transforma en "sociedad". Podríamos decir que nuestra sociedad rural afectada por la violencia comienza a urbanizarse en el sentido sociológico, en el sentido de que comienza a adquirir un comportamiento urbano.

Este proceso de urbanización se realiza exclusivamente por la aparición de actividades terciarias (servicios personales, comercio, transporte, servicios bélicos, etc.) sin ninguna conexión con la actividad secundaria de industrialización.

Los efectos socio-económicos son evidentes: el modo de vida urbano implica una actitud racional, anti-tradicional respecto del cambio social. Sin embargo, en este caso esta actitud no va acompañada de una industrialización que permita elevar los niveles de vida. En una palabra, podemos decir que en la sociedad afectada por la violencia tenemos las

\footnotetext{
${ }^{10}$ Para ampliar la teoría sobre la transformación de la sociedad-folk en sociedad urbana debido a la división del trabajo, es útil consultar e. C. Hughes, Personality Types and the Division of Labor, American Journal of sociology, 1928/33, 754/768 y Leopold Von Wiese and Howard Becker, Systematic Sociology (Nueva York, John Wiley \& Sons, 1932), pp. 222-225 et passim).
} 
actitudes urbanas sin los instrumentos propios de una sociedad urbana.

b) Aislamiento social

Dentro de las variables comunes a todas las sociedades rurales encontramos el aislamiento social, elementos que incluye Redfield dentro de la sociedad folk ( $C f r$. supra).

Este fenómeno ecológico es debido a la baja densidad demográfica y a la ausencia de comunicaciones que caracteriza las sociedades rurales. En los países subdesarrollados el aislamiento social se encuentra agudizado por la falta de transporte y la ausencia de comunicaciones de toda índole. En Colombia, en particular, el aislamiento es aún mayor. La población colombiana está concentrada en la zona montañosa y en los valles separados por montañas. Las veredas o vecindarios rurales se encuentran aislados no solamente de las ciudades sino también de la cabecera del municipio y de las otras veredas.

La violencia incrementó las migraciones rurales no solamente a la ciudad sino también entre las diversas localidades campesinas. Las fuerzas armadas, además de sus sistemas propios de comunicación, fueron un conducto humano de transmisión de noticias, de valores sociales, de normas de conducta, establecido entre la ciudad y el campo y entre los diversos vecindarios rurales.

Como resultado, las poblaciones rurales han entrado en contacto tomando conciencia de necesidades comunes y adquiriendo una solidaridad de grupo, al enfrentar el conocimiento de su realidad socioeconómica con el conocimiento de otros niveles de vida superiores, tanto rurales como urbanos.

Los patrones culturales locales comienzan a difundirse y se produce un fenómeno de asimilación de dichos factores, comenzando así un proceso de gestación de una subcultura rural colombiana. Respecto del cambio social, el hecho de haber creado una solidaridad de grupo (que Marx llamaría conciencia de clase) hace que el campesinado colombiano comience a constituirse en un grupo de presión en la base de la pirámide social. Grupo de presión que, mediante una organización, puede llegar a ser importante en las transformaciones de las estructuras sociales, políticas y económicas de Colombia. 
c) Importancia de los vecindarios en la vida social

Dado el aislamiento antes descrito, es lógico que el vecindario en la vida social de la comunidad rural sea de la mayor importancia. La actividad humana en esta sociedad tiene una referencia directa a la localización geográfica. La falta de la división del trabajo excluye casi completamente la necesidad de desplazarse a otro lugar. Por lo tanto, el vecindario desarrolla con la familia, la institución de control social más eficaz en la sociedad campesina. La sanción aprobatoria o condenatoria del vecindario tiene una gran influencia en la conducta del campesino.

Sabemos que hay una relación estrecha entre la fuerza del control social y la estandarización de los patrones de conducta. Los fenómenos de anomia se presentan rara vez en una sociedad aislada y de control fuerte. En esta comunidad se encuentra entre sus individuos poca capacidad de asimilación, ya que para poder llevar la vida en sociedad les ha bastado acomodarse mecánicamente a los patrones tradicionales de conducta. De ahí viene la coherencia del sistema de la sociedad folk del que habla Redfield; de ahí también la falta de experimentación y la falta de reflexión para fines intelectuales. La conducta es más espontánea que reflexiva y por eso la capacidad de asimilación es menor.

La violencia rompe los marcos del vecindario rural. Los grupos guerrilleros comienzan a convertirse en nuevos elementos de control a una escala más regional que veredal. La presión oficial se manifiesta en muchas ocasiones por primera vez, en las áreas rurales, ejerciendo presiones de todo género (desde la violencia física hasta los halagos económicos) a escala regional, sobre las comunidades rurales. También la posibilidad y en algunas ocasiones la necesidad de emigrar libera a los grupos rurales del control social de la comunidad vecinal. Los grupos de referencia para el control social se multiplican; además de la familia existen los grupos guerrilleros; además del vecindario propio hay grupos de campesinos perseguidos más o menos beligerantes; el ejército militar y los grupos de ejércitos civiles, los grupos urbanos que intervienen directa o indirectamente en la violencia y por ella en las comunidades rurales. Todos estos grupos con sus diferentes patrones y valores de conducta relajan el control social en una forma semejante a lo que ocurre en las ciudades. El campesino habituado a actuar sin reflexión ni crítica, de acuerdo con patrones, pierde toda norma de conducta y se irá adaptando, en cuanto le sea posible, a los diferentes grupos de referencia. La conducta anómica se generaliza en 
esta forma dentro del conglomerado campesino como un efecto del rompimiento del aislamiento social del vecindario. Las comunidades rurales que han sufrido el fenómeno de la violencia están abiertas a toda clase de contacto cultural.

El rompimiento de su aislamiento social ha hecho perder importancia al vecindario de la vida social del campesino y ha establecido nuevas instituciones a la escala regional y nacional que caracterizan la nueva subcultura originada por la violencia.

En forma similar a lo ocurrido con el aislamiento social se produce en el área rural un relajamiento del control social local por la multiplicación de controles que son independientes del lugar geográfico. Esta multiplicación de controles diversos se explica por la diversificación de las actividades rurales. Sin embargo, dicha diversificación no obedece a un fenómeno de desarrollo de la productividad económica, sino a actividades de destrucción, de defensa o simplemente de subsistencia, difícilmente enmarcables dentro de un plan de desarrollo socioeconómico para el país. Podemos decir también en este caso que encontramos fenómenos sociológicos de urbanización, sin los fenómenos concomitantes de industrialización y de creación de ciudades.

Los nuevos organismos de control y la relajación de éstos, han llevado a una conducta más reflexiva y más crítica, pero de acuerdo con una escala de valores completamente patológica.

d) Individualismo

El aislamiento produce en general la existencia de grupos y sociedades cerradas. Sin embargo, cuando a ese aislamiento se une el trabajo aislado de cada individuo, el individualismo surge como una secuela lógica. Este es el caso en las sociedades rurales de estructura minifundista o de ocupación estacionaria de las cosechas. Los intereses son entonces individuales y la colaboración sólo surge en función de éstos. Instituciones como "la minga", "la mano vuelta", "el convite", tienen un carácter transitorio y no contradicen sino que confirman la conducta individualista en cuanto ésta se entienda como resultante de la búsqueda de objetivos en función de intereses predominantemente personales. El individualismo es una actitud que se define por motivación. Sin embargo, la conducta 
social es un índice, y a veces el único conocido y conocible, de la motivación de los individuos.

Dada la predominancia del minifundista y del cosechero dentro de la población campesina colombiana, podemos asegurar que la actitud individualista es bastante generalizada, especialmente en las áreas más aisladas. Los hábitos colectivistas que tenían algunas comunidades indígenas, puede decirse que han desaparecido dentro de la mayoría de los campesinos colombianos.

La violencia rompe en gran parte el individualismo campesino. Las fuerzas oficiales introducen sistemas de conducta donde se hace indispensable el trabajo en equipo. En forma similar son organizadas por el gobierno las llamadas "guerrillas de paz", para combatir a los bandoleros.

Las fuerzas de guerrilleros, formal e informalmente constituyen elementos de trabajo colectivo que también quebrantan el sentido individualista de nuestro habitante rural.

Formalmente se establecen "Normas Organizativas de las Fuerzas Guerrilleras"11. En ellas los intereses colectivos priman sobre los intereses individuales.

Informalmente, los guerrilleros debían trabajar en equipo para todas sus labores tanto bélicas como de subsistencia. Inclusive se establecen grupos como el de pato, en donde por esfuerzo colectivo se construyó un trapiche, se sembró una huerta, se organizó la producción de panela y la rocería de los campos, así como las siembras, el deshierbe y las cosechas.

La solidaridad de grupo propia de toda comunidad marginal y en especial de todo grupo considerado fuera de la ley, se verifica plena- mente dentro de los grupos guerrilleros.

Dentro de los campesinos la violencia crea circunstancias por las cuales ellos tienen que romper con su individualismo; las migraciones conjuntas, la defensa de las comunidades rurales, la organización para la producción, etc., crean una mentalidad de cooperación, de iniciativa y de conciencia de clase, tenemos una situación social nueva en la comunidad rural colombiana, que hace que dicha comunidad constituya un elemento

${ }^{11}$ La violencia en Colombia, op. cit., p. 142. 
social con cohesión interna, con iniciativa y con dinamismo frente a las posibilidades del cambio social.

e) Conflicto con el extra grupo

Los grupos rurales descritos con las características anteriores son necesariamente cerrados "con un fuerte sentido de solidaridad", según la descripción de Redfield129, solidaridad interna que está generalmente en relación directa con el grado de conflicto respecto de los elementos extra grupo.

Nuestras comunidades rurales tienen, en efecto, una actitud de desconfianza respecto de las instituciones, de los líderes y en general de las personas que no pertenecen a su grupo social.

Las instituciones pertenecientes al extra grupo podemos clasificarlas en oficiales, eclesiásticas y privadas. Es necesario hacer notar que muchas de las instituciones oficiales, eclesiásticas y privadas pertenecían al mismo grupo campesino, en el sentido de que eran identificadas con la comunidad rural mucho más que con el gobierno, la iglesia u otra entidad de nivel nacional.

El empleo del pronombre personal de primera persona en plural, "nuestro", en relación a la iglesia (como edificio) al palacio municipal y algunas de las haciendas, nos revela ese sentimiento de solidaridad con dichas instituciones.

Sin embrago, la actitud respecto a instituciones oficiales a un nivel superior al municipal, no era una actitud de conflicto abierto sino más bien de reserva y aun de desconfianza; lo mismo podemos decir de la actitud respecto a entidades eclesiásticas y particulares no pertenecientes a la localidad.

No obstante, es indispensable distinguir en el área rural dos tipos de comunidades muy diferentes: la perteneciente al pueblo y las pertenecientes a las veredas. Dentro de estos dos tipos existía, antes de la violencia, una relación de acomodación en la cual las

12 Op. cit. 
comunidades veredales estaban subordinadas a la comunidad del pueblo; esta acomodación algunas veces se convertía en conflicto, especialmente por razones políticas. Razones políticas que posiblemente eran un símbolo para manifestar un conflicto latente ocasionado por la situación de inferioridad de las veredas respecto de la cabecera del municipio.

Entre las diferentes veredas encontrábamos también una relación de competencia que en ocasiones se resolvía por un conflicto, rara vez violento. Sin embargo, pocas veces encontrábamos una relación de acomodación entre una vereda y otra, y el conflicto común con la cabecera del municipio hacía que las tensiones veredales disminuyeran y se creara una relación de solidaridad entre las mismas veredas.

Con la violencia las relaciones humanas entre la sociedad rural se transformaron fundamentalmente. Las instituciones oficiales, eclesiásticas y civiles, aun de carácter local, fueron consideradas en muchas ocasiones como instituciones extra grupos rompiendo la integración de éstas al grupo campesino. Como por otro lado las relaciones con las mismas instituciones al nivel departamental o nacional se hicieron de conflicto abierto y muchas veces violento, también con estas instituciones al nivel local, se estableció una relación de conflicto.

La acomodación respecto del gobierno, la iglesia y los patronos se destruyó. Esta misma relación de acomodación entre la vereda y el pueblo también sufrió un cambio. Algunos elementos del pueblo se aliaron con las instituciones oficiales, eclesiásticas y civiles que estaban en conflicto con el grupo campesino y otras se solidarizaron con este grupo en contra de los anteriores. Los elementos del "pueblo" entraron en una relación de cooperación con los elementos de la vereda por una parte o con las instituciones extrañas por otra.

Las relaciones entre las veredas han tenido varias etapas; los ligeros conflictos anteriores a la violencia se agudizaron, adquiriendo un cariz netamente político al comienzo. El campesinado de base se agrupó bajo los símbolos de los partidos tradicionales, liberal y con- servador, en actitud de conflicto violento. Los grupos comunistas surgieron como tercer elemento, en ocasiones como grupo campesino de aquellos que no deseaban un conflicto con otros campesinos sino con las autoridades formales e informales. 
El primer efecto de la violencia fue dividir al campesinado. A medida que el estado de violencia se hizo crónico, se presentó un importante fenómeno de cambio social; en el caso de que la presión violenta del extra grupo disminuye y las necesidades socioeconómicas crecen, se crea un nuevo tipo de solidaridad entre los campesinos liberales, conservadores o comunistas. Esto ocurrió, por ejemplo, en el Valle del Cunday a principios del año 1961.

Este nuevo tipo de solidaridad es más orgánico que mecánico, más racional que sentimental y borra no solamente las divisiones existentes entre los grupos campesinos antes de la aparición de este fenómeno.

En relación a los líderes, antes del fenómeno de la violencia se encontraba en las sociedades rurales una concentración del liderazgo en el "pueblo" o cabecera del municipio. Allí se encontraban los líderes burocráticos, tradicionales y carismáticos. ${ }^{13}$ Algunos de estos últimos se encontraban también en las veredas, pero no tenían mucha influencia en las decisiones oficiales, en el gobierno de la comunidad rural a la escala municipal, reservándose una pequeña cuota de poder informal a la escala "veredal".

La estructura del liderato campesino cambió con la implantación de la violencia. Los líderes carismáticos de la vereda adquirieron una importancia muchas veces mayor que la de los líderes del "pueblo" o cabecera municipal. Los líderes tradicionales o gamonales del pueblo, que se adhirieron a las instituciones patrocinadoras de una violencia adversa perdieron su liderazgo dentro del resto del campesinado, lo mismo sucedió a los líderes carismáticos y por lo tanto dejaron de ser líderes carismáticos en el sentido propio del concepto.

Es muy lógico que en los procesos electorales haya surgido un nuevo tipo de gamonalismo veredal con el cual necesariamente tienen que pactar los directorios políticos, en vista a obtener una colaboración de la masa campesina.

Con relación a otras personas del extra grupo, podemos afirmar que el sentimiento de solidaridad o de desconfianza con respecto a ellas estaba estrechamente condicionado a

\footnotetext{
13 Clasificación tomada de Max Weber, Economía y sociedad, Fondo de Cultura económica de México, que es la aceptada por la generalidad de los sociólogos.
} 
la actitud que éstas observaron durante la violencia. En efecto, muchos elementos extra grupo, inclusive de clase alta y origen urbano fueron aceptados dentro del grupo campesino, siempre y cuando se manifestaran solidarios en su lucha armada; y muchos elementos genuinamente rurales fueron re- chazados si se manifestaban solidarios con grupos adversos en esta misma lucha.

La solidaridad con las personas se hizo más a base de intereses comunes que de origen ecológico, mucho más por motivos racionales que por motivos tradicionales.

El conflicto con los elementos extra grupo y la reestructuración de las relaciones sociales en las comunidades rurales cambia funda- mentalmente la estructura de nuestro campesinado, creando un nuevo tipo de solidaridad campesina más racional y que es la base de un conflicto con los elementos extra grupo que no se identifican con los intereses de esta comunidad.

\section{f) Sentimiento de inferioridad}

El sentimiento de inferioridad del campesino respecto de los habitantes urbanos ha sido generalmente aceptado por los estudiosos de los fenómenos sociales. Este sentimiento ha sido habitualmente descrito como un fenómeno psicológico individual. Sin embargo, en el caso de que este fenómeno represente una actitud colectiva podemos aplicarlo, haciendo las salvedades conceptuales del caso, en análisis psicológico social. El sentimiento de inferioridad del campesino se ejercía fundamentalmente respecto de las instituciones y de los individuos pertenecientes a la sociedad urbana, traduciéndose por diferentes tipos de relación, ya de acomodación, ya de conflicto. La violencia dio a los campesinos una seguridad en la acción en contra de elementos urbanos, de instituciones, personas y patrones de conducta, que los campesinos referían a la comunidad urbana. En realidad los grupos guerrilleros de campesinos no han hecho nunca incursiones directas en las grandes ciudades colombianas. Con todo, el sentimiento de inferioridad, en materia bélica, ha sido suplantado por el sentimiento de superioridad. En la "guerra de guerrillas" los campesinos tienen la conciencia de que han vencido sobre el ejército, de que han logrado derrotar una institución de tipo urbano, que constituye la base de la defensa de 
nuestras ciudades.

Haciendo caso omiso de la verdad o falsedad objetivas de este nuevo sentimiento, tenemos que constatar el cambio psicosocial que implica, ya que un elemento esencial para constituir un grupo de presión es que ese grupo tenga seguridad en la acción respecto a aquellos grupos sobre los cuales considera necesario el ejercicio de la presión social.

2 Variables propias de las sociedades rurales de países subdesarrollados

a) Ausencia de movilidad vertical ascendente

La movilidad social ha sido siempre considerada como un elemento de cambio social. Sin embargo, nos parece necesario distinguir entre una movilidad social simplemente material y una movilidad socio-cultural. La movilidad social material consiste en el simple paso de individuos de un grupo social a otro, de un área geográfica a otra, de un estatus o de una clase social a otras.

La movilidad social cultural implica necesariamente el cambio de las estructuras de los valores, de la conducta, y por ende de las instituciones sociales, como consecuencia de la movilidad material. La relación entre la movilidad social material y la movilidad sociocultural es evidente, tanto desde el punto de vista cuantitativo como desde el punto de vista cualitativo.

Cuantitativamente: Si el paso de individuos de un grupo a otro o de un área a otra se realiza en forma masiva, es muy difícil evitar que en el proceso de asimilación se produzcan cambios socio-culturales, tanto en los individuos que llegan como en los individuos que reciben. El conformismo de los que pasan no puede ser debidamente controlado.

Por el contrario, si el paso lo realiza un grupo pequeño y en forma lenta, es muy probable que los patrones socio-culturales de la sociedad que recibe permanezcan prácticamente inmutables y los elementos nuevos sean los únicos transformados por la 
movilidad social, ya que en este caso se impondría el conformismo como requisito para la aceptación de los elementos.

Cualitativamente, es necesario distinguir el tipo de individuos que se movilizan. No es lo mismo el ascenso de un líder que el ascenso de una persona sin influencia en su grupo social. También es necesario distinguir los requisitos de la movilidad social. Es posible que para una movilidad horizontal no existan exigencias de parte de la comunidad receptora, mientras que para una movilidad vertical as- cendente sea necesario ajustarse a los patrones de ascenso social de las instituciones que controlan ese ascenso, es decir, sea necesario el conformismo.

En el presente análisis consideramos la movilidad social no sola- mente desde el punto de vista material, sino desde el punto de vista socio-cultural, por cuanto en nuestro parecer este aspecto es el que más directamente interesa al estudio del cambio social.

No obstante que la movilidad social en el campo con relación a la ciudad es una característica general, en los países subdesarrollados presenta caracteres más agudos.

Es difícil hacer esta constatación respecto de la movilidad horizontal, si por ella entendemos la corriente migratoria hacia los centros urbanos. El rápido crecimiento de las grandes ciudades de los países subdesarrollados, debido fundamentalmente a la migración del cam- po, es un indicio de que la movilidad horizontal rural en estos países es mayor que en los países desarrollados. Además, a pesar de las deficiencias de los transportes, los factores de expulsión del campo y de atracción a la ciudad tienen una mayor importancia en los países no industrializados.

En cuanto a la movilidad vertical descendente, dada la existencia de círculos viciosos descendentes, dentro de la estructura socioeconómica de los países en desarrollo, es mucho más fuerte en éstos que en los desarrollados, especialmente en lo que a áreas rurales se refiere. El aumento de población rural no puede ser seguido por el aumento de la productividad. La subdivisión de la tierra recrudece el problema del minifundio, y aumenta con cada nueva generación. La mano de obra se abarata con el aumento de la población que no va acompañado de un aumento proporcional de oportunidades de trabajo y de productividad.

En lo que hace a la movilidad vertical ascendente, trataremos de analizar la situación 
en los países subdesarrollados, basándonos en un análisis de los canales de ascensión social en estos países.

Consideramos que este análisis nos permite ver tanto el aspecto cuantitativo como el aspecto cualitativo, para así tratar de determinar los requisitos impuestos por las instituciones que controlan el ascenso, requisitos que están estrechamente ligados al aspecto cuantitativo, a causa del volumen de población que pasa de una clase a otra.

Dentro de estos canales queremos considerar los siguientes como los principales: el canal económico, el cultural, el político, el burocrático, el militar y el eclesiástico.

\section{Canal económico}

La posesión de bienes de producción y bienes de consumo constituye, en general, un medio rápido de ascenso en la escala social. En un régimen de empresa privada, la habilidad para enriquecerse es absolutamente relativa a la calificación como empresarios que tenga el promedio de la población. En otras palabras, la competencia para ascender en lo económico, no requiere necesariamente una calificación a largo plazo, como es el caso en el terreno de lo cultural, lo militar o lo eclesiástico. La competencia en la posesión y utilización de bienes y servicios no requieren más calificación que la relativa, sin ninguna exigencia por parte de la naturaleza misma de este canal de ascenso.

Poseer y utilizar es algo que todo el mundo sabe hacer. Es mucho más fácil aún que administrar o mandar. Por eso el canal económico es, en sí mismo, aún más rápido que el burocrático y el político.

Por otra parte, del ascenso económico dependen las necesidades vitales del hombre en un régimen de empresa privada y aun en un régimen colectivista en lo que a los bienes de consumo se refiere.

Por estas dos razones, entre otras, la oclusión del canal económico para el ascenso social constituye una de las más serias frustraciones sociales, especialmente en los países subdesarrollados en donde la calificación humana es baja y el ingreso nacional es reducido. Cuando esta frustración se hace consciente y se abren posibilidades de solución, 
aparece el verdadero "problema social". Ahora bien, una de las características de los países subdesarrollados es la de concentración de los bienes y de los servicios en pocas manos. Los pocos poseedores, en general, obstruyen los canales de ascenso económico mientras el abrirlos no les aporte una ventaja. Los que comienzan a salir de su mentalidad feudal de poseer en lugar de producir, los que comienzan a tener una mentalidad capitalista, de mayor productividad, abrirán los canales económicos a aquellos que puedan llegar a ser mejores consumidores. Los abrirán también en la medida en que una presión social de abajo hacia arriba haga peligrosa la estructura económica de la que estos pocos poseedores usufructúan. Sin embargo, estas dos circunstancias (mentalidad de productividad y presión social de base) son dos índices de comienzo de desarrollo. En donde no existen, la obstrucción del canal económico de ascenso es casi total. Esta oclusión es mayor en las áreas rurales; la baja productividad de la empresa agropecuaria y la economía de subsistencia en las áreas rurales de los países subdesarrollados, hace que la demanda efectiva de productos aumente más lentamente con el aumento de ingresos per cápita que lo que aumenta en las áreas industriales. Además, el tradicionalismo rural impide el cambio rápido de los hábitos de consumo en la población campesina. Esto hace que, aunque exista la mentalidad entre los poseedores de abrir canales de ascenso económico para aumentar el consumo y la demanda, los habitantes del campo sean los últimos en ser considerados como futuros clientes.

Respecto del miedo a la presión social, los campesinos también están en condiciones de inferioridad. El aislamiento social, el individualismo, el tradicionalismo, hacían difícil que el campesino se constituyese en un grupo de presión. Sin contactos sociales que des- encadenaran cambios de esas y otras variables, el campesinado no constituirá un peligro para la estructura económica vigente.

Como lo anotamos atrás, la violencia hace que el campesinado comience a constituirse en un grupo de presión. La violencia que dio a éste conciencia de sus necesidades, conciencia de sus propios recursos humanos para superarlos, lo saca de la pasividad tradicional y lo organiza con la solidaridad de grupo para fines bien específicos. Desarrolla el conflicto respecto del extra grupo y lo institucionaliza.

En lo que se refiere directamente al ascenso social por el canal económico, la violencia tuvo dos efectos primordiales: en primer lugar creó los contactos necesarios 
para despertar la conciencia campesina respecto de su miseria, agudizando ésta en todas las áreas en donde el fenómeno se produjo; en segundo lugar y simultáneamente, introdujo instrumentos para lograr fines económicos en todas las escalas de la jerarquía social. Desde el efecto político-económico de asegurar un botín burocrático para la clase gobernante, pasando por la adquisición de grandes fincas devaluadas por la violencia ${ }^{14}$, por la confiscación de las cosechas, la abstención de pagos de deudas a personas públicas y privadas, hasta el negocio de tráfico de armas, la confiscación de animales y pequeñas propiedades, etc. el campesino, junto con la conciencia de su miseria, adquirió por fenómeno de la violencia instrumentos considerados como anómicos por la sociedad colombiana, pero que resultaban eficaces para el ascenso social. Tanto en este canal como en los que analizaremos a continuación, veremos cómo la oclusión de las vías normales de ascenso, siempre y cuando exista una presión en la escala social para subir, produce la creación de canales anormales o patológicos, si estos canales se presentan como más eficaces. ${ }^{15}$

Después de la violencia el campesino ha tomado el hábito de bus- car su ascenso económico o al menos su subsistencia por cualquier canal. Aceptando la existencia de una criminalidad definida entre los grupos guerrilleros, las nuevas generaciones de campesinos podrán combatir eficazmente la violencia si no se abren canales normales de ascenso económico que resulten eficaces para la mayoría de la población rural.

\section{Canal cultural 16}

Cuando hablamos de ascenso social cultural queremos referirnos a la adquisición de aquellas formas culturales que pertenecen a una clase o estatus social superiores. Estas formas se pueden adquirir directa o indirectamente. Indirectamente, si se ha llegado a un

\footnotetext{
${ }^{14}$ La violencia en Colombia, opcit., p. 274 et passim.

15 Empleamos las palabras normal y anormal con relación a los patrones culturales aceptados formalmente por la mayoría de la sociedad colombiana.

16 Por "cultura" entendemos el conjunto de valores, patrones de conducta e instituciones que se transmiten de una generación a otra, dentro de una sociedad. No incluye ningún juicio de valor favorable.
} 
determinado estatus o clase por un canal distinto al cultural y se adquieren esas formas por integración y asimilación a la nueva clase o estatus. Directamente por la integración y asimilación formal de los nuevos valores e instituciones que se realiza mediante la educación institucionalizada.

Así queremos referirnos a esta última forma de adquisición directa.

a) Enseñanza primaria

Dada la escasez de planteles educativos y de maestros para la enseñanza primaria en los países subdesarrollados (alto grado de analfabetismo), dada la concentración urbana de la enseñanza, dado el ausentismo escolar, debido principalmente a razones económicas, las posibilidades de adquirir nuevas formas culturales están limitadas a una parte de la sociedad y en una proporción desfavorable para el campesino. En Colombia, el sistema rural de escuela alternada agrava aún más esta situación. La escasez de planteles y de horas de clase y la concentración urbana hacen que, en general, haya una correlación positiva entre estatus económico y nivel de escolaridad primaria. Esta correlación se hace mayor si consideramos que el ausentismo escolar, debido en gran parte a la necesidad de hacer trabajar a los niños, tiene una gran influencia en la escolaridad.

En esta forma vemos cómo la oclusión del canal de ascenso eco- nómico tiene una influencia importante en la oclusión del canal de ascenso cultural en esta fase primaria.

b) Enseñanza secundaria

La incidencia del factor económico sobre el canal cultural se hace predominante en el nivel secundario de enseñanza, en aquellos países en los cuales, como en Colombia, la enseñanza secundaria privada y eclesiástica representa una mayoría de la enseñanza secundaria (82\% de los alumnos). Es lógico que ésta, sin subsidios y sin controles eficaces, es costosa y se hace patrimonio casi exclusivo de la clase económicamente alta. Los escasos colegios oficiales o de bajas pensiones constituyen una minoría. Sin embargo, aun dentro de estos mismos planteles, las influencias provenientes de los detentores del poder 
económico impiden la capilaridad total de dichos establecimientos. Respecto al resto, la influencia de lo económico es claramente predominante.

Podemos afirmar, sin temor a equivocarnos, que el ascenso cultural, en esta etapa secundaria de la escolaridad, está determinado por las posibilidades de ascenso económico. Si éste está obstruido, lo estará también aquél.

c) Enseñanza universitaria

La enseñanza universitaria en los países subdesarrollados no es especialmente costosa en cuanto a pago de pensiones se refiere. Las instituciones privadas no tienen tanta importancia como para que el promedio por matrícula y derechos de estudio que deben pagar los estudiantes sea demasiado alto (en Colombia aproximadamente un 50\% de los estudiantes). Esto no excluye la existencia de pensiones al- tas para esa minoría de universitarios que asisten a las universidades privadas.

La oclusión de esta etapa del canal cultural se produce más por las limitaciones cuantitativas y las limitaciones a la capilaridad de la etapa anterior (de la enseñanza secundaria). El cupo es generalmente muy reducido con relación a la demanda. En Colombia, donde tenemos un freno tan acentuado en la enseñanza secundaria, de 16.000 estudiantes que se presentaron como aspirantes a ingresar a la universidad en 1958, solamente lograron hacerlo 9.800. Además se calcula que de los ingresados solamente el 40\% llega al final de la carrera. ${ }^{17}$ Esta restricción cuantitativa hecha a base de selección perfeccionista tiene múltiples causas (dentro de las cuales está el burocratismo). Sin embargo, es necesario reconocer que la pobreza de las universidades oficiales con relación a la necesidad de dirigentes que tienen los países subdesarrollados, es bastante notoria. Esto hace que el factor económico determine en buena parte la oclusión del canal cultural en esta fase. Con todo, es necesario llevar el análisis más adelante. El perfeccionismo en la selección y la especialización en que insisten los programas universitarios, representan en parte instrumentos de la élite intelectual para obstruir el canal cultural de ascenso y descartar lo más posible la competencia que pondría en peligro

${ }^{17}$ Datos tomados de la Estadística de la Educación Superior, 1958, Asociación Colombiana de Universidades, Bogotá, D. e., 1961. 
sus privilegios. Sabemos que toda especialización, al diversificar la competencia, la debilita. esto explica por qué, no obstante, aunque ni la estructura de los países en desarrollo ni las tendencias universitarias actuales lo aconsejen, se insista tanto en especializaciones propias de países industrializados y en seleccionar un mínimo de futuros profesionales basándose en criterios perfeccionistas.

Como conclusión, podemos afirmar que el canal cultural de ascenso en esta fase superior, se encuentra obstruido por factores económicos y culturales.

Es necesario hacer notar que en el nivel profesional es muy difícil poder ascender sin un criterio conformista respecto de las élites culturales en los países en desarrollo. Estas élites, por tener el control de ascenso, es raro que lo toleren por individuos que quieran mermar ese control. Claramente vemos en la universidad cómo el nivel de conformismo asciende a medida que se acerca el fin de la carrera y se necesita ser aceptado por la élite profesional que se mantiene como tal gracias a las estructuras vigentes.

Estos requisitos de ascenso hacen que la movilidad social por este canal sea más de carácter material que de carácter sociocultural, lo que implica una ausencia de cambio en las estructuras sociales del país.

Respecto de las áreas rurales, sería interesante hacer un estudio más a fondo del porcentaje de estudiantes de origen campesino que está en la universidad ${ }^{18}$ y en la enseñanza secundaria. Dada la estructura antes descrita, podríamos afirmar que es una minoría. En esta forma, la obstrucción del canal cultural es aún más profunda respecto del campesinado.

No obstante algunas exigencias esporádicas de instrucción formal que los grupos guerrilleros hacían a sus miembros no podemos decir que la violencia hubiera constituido un nuevo canal en el ascenso social por la vía cultural formal. Por el contrario, la ya precaria instrucción de nuestras zonas rurales fue afectada por la destrucción de las escuelas, la fuga de los maestros y la imposibilidad de los niños para asistir a los planteles educacionales. Sin embargo, es importante anotar que, después de haber sufrido el

\footnotetext{
18 Robert Williamson, "el estudiante colombiano y sus actitudes", Facultad de sociología, Monografía № 13, Bogotá, 1962. Trae un porcentaje de 6,2 de hijos campesinos.
} 
proceso, los campesinos tienen una conciencia mayor de la necesidad de educarse y si, por los otros factores antes anotados, el campesinado se ha constituido en un grupo de presión, esa necesidad sentida de instrucción y de progreso será uno de los objetos primordiales de su acción.

Durante las encuestas hechas para llevar a cabo proyectos de re-forma agraria, se ha podido constatar como quizá la primera necesidad sentida por el campesinado colombiano de las zonas de violencia, es la necesidad de una escuela para poder mandar a sus hijos.

La violencia no ha constituido un progreso en la instrucción formal del campesino sino por la reacción que ha producido y por el deseo de progreso que ha sembrado entre los campesinos azotados por el fenómeno.

\section{Canal político}

Como el canal de ascenso cultural, al canal del ascenso político lo encontramos también dividido en niveles diferentes y en sus aspectos de formal e informal. Por ascenso político entendemos, en general, el ascenso en el poder de un gobierno coercitivo sobre las personas. Este gobierno coercitivo puede hacerse dentro del estado o por medio de las presiones individuales y colectivas. Nosotros tomaremos el con- cepto restringido del poder político, considerándolo como "acción política en cuanto tal”, es decir, dentro de la estructura del Estado, como acción política formal. ${ }^{19}$ Ahora bien, esta acción política formal se ejerce por medio de funciones del estado. Por eso nos limitaremos a examinar la posibilidad de ascenso en las posiciones políticas del gobierno, excluyendo de este canal la administración (que está considerada en el canal burocrático). Dentro de estas posiciones encontramos las del nivel nacional, departamental y municipal.

Las de nivel departamental y nacional están prácticamente vedadas para la masa campesina en los países subdesarrollados. Fuera de algunas pocas excepciones en donde existen verdaderos partidos agrarios de raigambre popular, y de fuerza electoral, el

${ }^{19}$ Cfr. Max Weber, op. cit. 
campesinado está excluido de cargos a estos niveles.

Respecto de los cargos a nivel municipal, debemos analizar los procesos de ascenso y sus requisitos para constatar la capilaridad del canal político, aunque sea en esta primera etapa.

En general podemos decir que estos criterios de selección de los funcionarios oficiales en los países subdesarrollados y en América Latina, en especial, no se hacen a base de criterios objetivos de eficiencia profesional y administrativa, sino basándose en criterios económicos, sociales y electorales.

La institución del "gamonalismo", aunque es más una institución informal de acción políticamente orientada ${ }^{20}$ que una institución política formal, tiene una gran influencia en los criterios para proveer los cargos oficiales. El "gamonal" 21 es un candidato en sí mismo o es un elemento decisivo en la elección del candidato o consejero, alcalde, juez o cualquier otro cargo a escala municipal. Su influencia está basada en la superioridad económica y social que tenga trascendencia en los fenómenos electorales. Aun en países en donde (como en Colombia) la elección de la mayoría de los funcionarios municipales es más administrativa que electoral, la influencia sobre los votos es un criterio decisivo en la elección de éstos. Sin embargo, dentro de este canal no consideraremos los funcionarios que no tengan un poder de decisión de carácter coercitivo sobre los ciudadanos, para diferenciar el cauce burocrático del canal político. Dentro de los funcionarios formalmente políticos tenemos a los consejeros municipales, al alcalde y al juez (para el caso colombiano). A los militares no les consideraremos como funcionarios y por eso dedicaremos un análisis especial a ese grupo social. Los otros funcionarios municipales pueden tener una influencia política pero no son funcionarios políticos en el sentido explicado arriba.

En algunos países subdesarrollados, como en Colombia, ciertos funcionarios políticos municipales son nombrados por las autoridades regionales y centrales. En este caso, el nombramiento se hace principalmente a base de la adhesión que los candidatos presten

\footnotetext{
${ }^{20}$ Cfr. Max Weber, op. cit.

21 “Gamonal" se llama en Colombia al líder tradicional a la escala local.
} 
a la política gubernamental, siempre y cuando esta adhesión esté unida al prestigio social en su comunidad. Son, pues, definitivos en este caso, como factores de ascenso político, aquellos que determinan los criterios de los mandatarios centrales y aquellos que constituyen el prestigio social a escala municipal.

Naturalmente que para hacer afirmaciones fundamentadas sobre dichos factores sería necesario hacer investigaciones detalladas y científicas. Con todo, a manera de hipótesis de trabajo podemos afirmar que los que detentan el poder, por ser una minoría, que en general no ha ascendido gracias a calificaciones y criterios objetivos de selección, tendrán como características:

La actitud conservadora respecto de las estructuras vigentes.

La inseguridad social.

La agresividad respecto de los miembros del extra grupo.

1ํAl hablar de las estructuras vigentes, nos referimos aquí principal- mente a los canales de ascenso social que ya analizamos: los canales económico y cultural. Creemos que la minoría política está interesada en los mecanismos de obstrucción de esos canales porque en su modificación va su propia cabeza, si no como individuos, ciertamente como clase privilegiada. Por esto, únicamente a los conformistas les es otorgado el ascenso social.

Si esta élite política no es en sí misma poseedora de los bienes de producción, depende estrechamente de la élite económica de la cual es subsidiaria en su vida pública y por lo tanto en su vida personal, ya que la política económica, tan básica en política general de los países subdesarrollados, no podrá llevarse a cabo sin la colaboración de esa élite.

Además, si pertenece a la élite cultural (lo que generalmente debe ser el precio que paga el jefe político a la clase dirigente por no pertenecer a la élite económica), la influencia del poder económico también se ejerce directa e indirectamente, como lo explicamos al hablar del canal cultural, de ascenso social.

2ํㅡㄴ La inseguridad social en la posición directiva es un resultado de la subjetividad en los criterios de ascenso. El individuo que asciende depende de otra persona y no de requisitos objetivos e impersonales, que le aseguren su estabilidad ocupacional. 
3ํㅡ La agresividad es un resultado natural de la situación como mino- ría y como minoría insegura.

Las características de la élite política que consideramos atrás, producen una oclusión del canal político de ascenso social para los funcionarios políticos que dependen de su designación, de la minoría política, más aún, de las personas mismas de esa minoría que ejerce el poder central. Dentro de los factores de oclusión, el factor económico con y por el cultural parece predominante. El criterio fundamental para el ascenso político tiene que ser, por lo tanto, el conformismo respecto de las personas de la clase dirigente, claro está que ante una igualdad en el grado de conformismo, se escogerá al más capacitado. Sin embargo, esta estructura del ascenso político hace que la movilidad vertical sea puramente material y que las estructuras socio-culturales se preserven de todo cambio social.

En cuanto al prestigio social a la escala municipal, vemos que el factor económico es igualmente predominante. En la influencia política del gamonal debemos considerar este factor como básico. La simpatía personal, la habilidad, deben estar subordinadas a un respaldo económico propio o ajeno. Sin embargo, a la escala municipal las dos primeras cualidades tienen una relativa importancia, ya que las relaciones primarias también la tienen; más aún en el área rural.

El prestigio social no es solamente la base de la selección de los funcionarios nombrados en forma jerárquica sino de aquellos elegidos en forma democrática. Por eso, estos criterios de prestigio social rigen también el ascenso político de los funcionarios elegidos.

Con todo, la influencia del factor económico no actúa únicamente a través del prestigio, sino directamente respecto de los funcionarios elegidos. El proceso electoral se hace bajo una serie de presiones económicas tales como la amenaza de despido o la promesa de alguna prebenda. Las elecciones, en los países subdesarrollados, aun sin mencionar el fraude electoral, son dirigidas por las minorías a través de los directorios políticos centralizados y de los gamonales, a través de presiones económicas, sociales y religiosas que tiendan a procurar el respaldo a las estructuras vigentes, a consolidar la oclusión de los canales de ascenso social. Es decir, presiones que hagan seleccionar únicamente a los elementos conformistas. 
En esta forma vemos cómo el canal político de ascenso social está obstruido, en los países subdesarrollados, para una mayoría de la población que no tiene recursos económicos ni amistad personal con los detentores del poder económico, ni cultura formal suficiente unida al poder económico y/o a la amistad en referencia: amistad que está liga- da estrechamente al conformismo respecto de las estructuras vigentes.

La violencia estableció un nuevo sistema de gobierno informal en las áreas campesinas en donde surgió. Aunque sería difícil determinar el porcentaje de antiguos líderes tradicionales o gamonales dentro del nuevo liderazgo guerrillero, es evidente que muchos de estos nuevos jefes no hubieran nunca logrado el poder que adquirieron por medio de la violencia ${ }^{22}$ dentro de las estructuras normales de ascenso social.

Los campesinos a quienes había sido vedada toda posibilidad de influjo en el gobierno de su propio destino y de los destinos del país, encontraron en las diversas escalas del nuevo poder establecido por la violencia la oportunidad de ascender.

Se ha hablado de la existencia de repúblicas en el interior del país, se sabe que hay zonas controladas por jefes guerrilleros. El hecho es que a la escala regional ha surgido un gobierno informal y anónimo que tiene, en ocasiones, más poder que el gobierno legal.

Como dijimos antes, no es de extrañar que los directorios políticos traten de pactar con los nuevos líderes. El gamonalismo tradicional comienza a perder influencia en favor de un liderazgo guerrillero, mucho menos conformista. Esta transformación de poder ha influido sobre la estructura social de nuestras comunidades rurales. La clase media que habita en los núcleos centrales de los municipios ("pueblos"), que usufructuaba los beneficios del poder, de la administración y del control económico y social en general, ha perdido su fuerza por la importancia adquirida de esos grupos periféricos capitaneados por nuevos jefes en las veredas de los municipios.

Podemos decir que, en cierta manera, el poder político informal se ha democratizado en nuestras áreas rurales y ha adquirido una actitud francamente anticonformista, actualmente en forma patológica y anónima. Sin embargo, constituye una base para la promoción del campesinado veredal que hasta entonces había sido un

${ }^{22}$ La violencia en Colombia, op. cit., capítulo VI, Semblanzas de Jefes Guerrilleros. 
grupo marginal, tanto respecto del país como de la misma comunidad rural.

Si la Acción Comunal, la reforma Agraria y los demás movimientos populares encauzados por el gobierno dentro de las comunidades agrícolas no logran abrir canales normales (claro está indirectamente) para el ascenso político de los líderes campesinos de base, la violencia seguirá siendo el único canal político de ascenso efectivo para el campesinado colombiano no conformista.

De todas maneras, aunque surjan nuevos canales de ascenso normal la estructura de éstos será necesariamente diferente de la de los canales actualmente existentes. El requisito para el ascenso futuro no podrá ser más el conformismo político; los nuevos pactos con los líderes campesinos tendrán que ser hechos a base de la influencia popular que éstos tengan. Influencia que, a la vez, estará cimentada más en la eficacia que en criterios subjetivos.

\section{Canal burocrático}

El canal burocrático de ascenso social es el que se realiza a través de los cargos exclusivamente administrativos como en parte lo explicamos antes. Es decir, con cargos que tengan funciones ejecutivas dentro de normas preestablecidas y en el campo de la organización tanto pública como privada. Por lo tanto es necesario considerar el ascenso burocrático dentro de la administración pública y de la privada.

\section{Burocracia pública}

Los criterios de ascenso social dentro de la burocracia oficial siguen (como los definimos en el caso del canal político) criterios más subjetivos que objetivos como sucede en los países subdesarrollados en general, y muy especialmente en los latinoamericanos ${ }^{23}$. Dentro de estos criterios subjetivos está el de la influencia política, social y económica que

${ }^{23}$ Cfr. Handlin, "Clases sociales en América latina", Ciencias sociales. Unión panamericana, Washington, D. C. 
pueda tener el candidato a empleado a los ojos del funcionario empleador. No quiere decir que estas influencias no puedan ser controladas objetivamente, por ejemplo por medio del número de votos puestos en la zona de influencia, por el prestigio familiar, por el ingreso per cápita, etc., etc. en lo que tratamos de insistir aquí es en que esos criterios se reflejan a través del sujeto que hace la elección.

También entran dentro de estos criterios subjetivos la simpatía personal del candidato, la afinidad ideológica y los compromisos familiares y de amistad.

Del concepto de criterio subjetivo se excluye el de la calificación profesional relativa a la función por llenar. No queremos en ninguna forma excluir totalmente los criterios objetivos de los criterios de movilidad ascendente. Lo único que queremos establecer es la prioridad de los criterios subjetivos.

Dentro de éstos creemos que los que están condicionados por la influencia política y económica son los más importantes para el ascenso social.

La burocracia es, en los países subdesarrollados, el medio más común para trabajar. En ella encontramos el porcentaje proporcionalmente más fuerte de inversiones del presupuesto nacional ${ }^{24}$ y la menor exigencia de calificación profesional. Por esta razón el número de candidatos a la burocracia oficial excede al número de oportunidades. Este excedente en la oferta de trabajo es aprovechado por el empleador mediante la exigencia de aquellas cualidades en el candidato que le den una seguridad respecto a la estabilidad de su propio empleo.

Como explicamos con anterioridad, las posiciones ocupadas gracias a criterios subjetivos son posiciones inseguras por depender más de las personas que de los requisitos universales preestablecidos (como sucede en los países desarrollados, en donde hay una carrera administrativa relativamente estricta y eficaz). Las calidades que dan más seguridad son las provenientes de la influencia política y de la posición económica del candidato al empleo.

La influencia política del empleado garantiza al empleador el respeto de los políticos que participan en el gobierno directamente como funcionarios, e indirectamente

\footnotetext{
${ }^{24}$ En 1961 el presupuesto para burocracia es aproximadamente el 30\% del presupuesto nacional. En Bogotá es aproximadamente el $60 \%$ para el mismo año.
} 
por los órganos de los partidos de los cuales depende su propia posición.

La influencia económica, además de obrar indirectamente sobre los políticos (según lo vimos cuando tratamos el canal político) garantiza una posibilidad de ascenso dentro de la empresa privada, en el caso de retiro de la burocracia pública.

Podemos concluir que, especialmente en los países subdesarrollados, el criterio económico de los que otorgan los puestos influye pre- dominantemente por y con el criterio político. Esto produce el hecho de que en estos países gran parte de la lucha política esté motivada por la perspectiva de reparto del botín burocrático y de que la ideología política de los empleados oficiales siga los vaivenes de los resultados electorales y políticos en general. Es interesante, desde el punto de vista de la sociología política, el efecto producido en Colombia por el establecimiento de la paridad administrativa. La lucha burocrática se desplazó al seno de cada uno de los partidos tradicionales, produciendo escisiones profundas en éstos con claras consecuencias burocráticas para las fracciones internas.

En esta forma, el ascenso social por el canal burocrático está condicionado por las oclusiones existentes en los canales económico y político, es decir que el ascenso burocrático oficial depende, en gran parte y en última instancia, del conformismo con la minoría que detenta los poderes económico, político y cultural.

\section{Burocracia privada}

Para establecer los criterios de ascenso dentro de la burocracia privada es necesario distinguir el género de empresa privada en que ésta se emplee. si se trata de una empresa de carácter más feudal que capitalista, los criterios serán más subjetivos que objetivos.

Si se trata de una empresa de carácter más capitalista que feudal, los criterios serán más objetivos que subjetivos. En este sentido los criterios subjetivos tendrán una orientación más negativa que positiva, es decir que se usarán más criterios de exclusión que de promoción. Dentro de éstos, uno de los principales es el conformismo del candidato. Sería bastante difícil que un individuo calificado pero inconformista lograra 
ascender en la escala burocrática privada. Esto nos hace concluir que aun a esta escala, la minoría privilegiada mantendrá el control de la situación sosteniendo la estabilidad de las estructuras actuales e impidiendo el ascenso que no estabilice su propia posición.

De los efectos principales que tuvo la violencia sobre la administración pública, querernos anotar los tres siguientes: 1o Establecimiento de un sistema militar administrativo informal; 2oㅡㄹ Descentralización de la administración; 3ํㅡㄹ Aparición de nuevas presiones para controlar los cargos administrativos.

a) Establecimiento de un sistema militar administrativo informa

Las guerrillas tuvieron un sistema militar administrativo informal. Como nos lo narra el libro La violencia en Colombia, había diversos niveles en la organización guerrillera, desde la guerrilla propia- mente dicha o escuadra, hasta la sección, la compañía, la agrupación guerrillera y la división guerrillera. Toda la administración militar tuvo que desarrollarse dentro de esta jerarquía y se crearon cargos no militares de administración como el de Comisario político, jefe de la Comunidad, Parcelador, Responsable de cada vereda y secretario General. ${ }^{25}$

Las normas impuestas a los guerrilleros contenían, además de prescripciones bélicas, una serie de principios administrativos elementales. En los establecidos por el Frente Democrático de Liberación Nacional de Colombia, se exigía para ascender al grado de oficial, además de los conocimientos militares, conocimientos políticos de tipo marxista, saber leer y escribir, tener nociones mínimas de ortografía y saber las cuatro operaciones de aritmética, además de disponer de buena conducta en su vida pública y privada.

La administración de justicia comienza a practicarse entre los guerrilleros, y aun dentro de aquellos grupos campesinos que eran objeto de la impunidad. Los códigos informales sobre sanciones y estímulos eran formas militares y administrativas de controlar a la población campesina en general y en especial a los grupos de combatientes.

${ }^{25}$ La violencia en Colombia, op cit., capítulo V. 
Posteriormente se han multiplicado en Colombia las llamadas "repúblicas independientes", a las que la autoridad oficial no tiene acceso; dentro de ellas se ha organizado una administración paralela a la administración oficial, con nuevos cargos y nuevas funciones. Esta nueva administración informal ha constituido un canal de acceso burocrático, con criterio selectivo diferente, basado en la calidad bélica, en el sectarismo político y en una habilidad elemental para la administración como líder carismático.

b) Descentralizado de la administración

La administración informal anteriormente descrita comienza a gozar de una gran autonomía regional. Los comandos revolucionarios se establecen con criterios eminentemente prácticos en relación a las condiciones locales y a la actividad guerrillera. La violencia en Colombia nos describe los Comandos existentes durante la primera etapa:

Comando de las Fuerzas Revolucionarias de los Llanos Orientales.

Comando revolucionario de Santander.

Comando de las Fuerzas revolucionarias de La palma y Yacopí.

Comando de las Fuerzas revolucionarias del sur del Tolima.

Comando del Oriente del Tolima.

Comando de Sumapaz.

Comando de Pavón.

Comando de las Fuerzas de Autodefensa de Gaitania.

Comando de las Fuerzas de Autodefensa del Tequendama.

Comando de río Chiquito y Símbola-Páez.

Comando de Nare.

Comando de Anorí.

Comando Guerrillero de La Rivera.

Como dice Monseñor Guzmán: “estos comandos, con excepción de algunos de los 
Llanos, no lograron nunca coordinarse ni ejecutar acciones combinadas" 26 .

La descentralización es pues autónoma y no coordinada. Las comunidades periféricas y locales adquieren una mayor importancia que los grupos centrales administrativos de la administración oficial. La oportunidad de esta descentralización y la movilidad descendente se incrementa respecto de los estratos más bajos de la sociedad rural colombiana.

c) Aparición de nuevas presiones para controlar los cargos administrativos

La administración oficial, como vimos antes, además de un cierto grado de competencia exige un conformismo riguroso para el ascenso burocrático. Este conformismo garantiza el control jerárquico de las clases dirigentes hasta los últimos grados de la administración pública. En la nueva administración informal los cargos y los ascensos comenzaron a otorgarse con criterios distintos, muchos de ellos considerados antisociales, pero en todo caso basados en valores más fácilmente asequibles para la mayoría de la población. La selección se hacía más por presiones de base que por decisiones de grupos descentralizados y lejanos. El mismo jefe guerrillero estaba sujeto a las presiones de aquellos con quienes convivía y de quienes dependía en su prestigio, en su seguridad y en su vida. Para el ascenso dentro de esta administración informal, el conformismo con las estructuras vigentes era un obstáculo y se exigía otra clase de conformismo: el acuerdo irrestricto en la actitud revolucionaria.

No solamente sobre esta administración informal se ejercieron las presiones de los nuevos grupos campesinos organizados. Sabemos cómo en la administración de justicia, en el cambio de funcionarios judiciales, influye decisivamente la presión de los grupos guerrilleros. Igualmente sabemos que muchos otros cargos tienen que respetar las opiniones de los grandes jefes regionales de los grupos bélicos.

Como resultado de la violencia, podemos afirmar que muchos campesinos en

${ }^{26}$ La violencia en Colombia, op cit., p. 163. 
diversas escalas de la jerarquía administrativa se han acostumbrado a ejercer presiones. La masa campesina afectada por el fenómeno también se ha acostumbrado a ejercer presiones sobre la administración, ha encontrado un canal de ascenso burocrático a su alcance que no tenía dentro de la estructura administrativa oficial. En el caso de que la administración pública no fije criterios suficientemente objetivos y no cree los instrumentos para que la mayoría de nuestra población pueda ajustarse a dichos criterios, la administración informal seguirá siendo un canal más eficaz para el ascenso burocrático en la escala social.

Canal militar

El canal militar de movilidad social ascendente está constituido por todo el escalafón formal del ejército, la marina, la Aviación y la policía. La función de las instituciones militares es la de la conservación del orden establecido. En los países subdesarrollados es la élite minoritaria la más interesada en conservar ese orden del cual dependen sus privilegios. Por otra parte, la vida económica del ejército depende del presupuesto oficial aprobado por el parlamento y, en ocasiones como en Colombia, los grados más altos son conferidos o aprobados también por éste. En esta forma las Fuerzas Armadas también dependen, en un aspecto capital, del grupo dominante y éste a su vez dependerá del ejército para el mantenimiento del orden.

En general, por estar en condiciones inferiores en lo político, lo cultural, lo económico y lo burocrático, las instituciones militares han sido el instrumento de los grupos dominantes. Como habitualmente estos grupos no son verdaderamente populares y no cambian las estructuras que no favorecen a la mayoría, los disturbios del orden público en los países en desarrollo son bastante frecuentes. Es necesario, entonces, cambiar popularidad por bayonetas. Cuando la primera no existe se recurre a la segunda. Naturalmente que los jefes militares pueden escoger el subgrupo político al que quieren apoyar dentro de esta élite. Cuando ejercen directamente el poder gubernamental lo hacen siempre apoyados por un sector de los poseedores, y el gobierno militar caerá cuando este apoyo cese y no sea reemplazado por otro. De esta forma, el control de la minoría dirigente se realiza mediante unos compromisos con el poder militar. 
La élite política, económica y cultural estará dispuesta inclusive a dar el gobierno del país a las Fuerzas Armadas, a condición de que se conserven las estructuras vigentes. Los militares harán respetar a la clase dominante hasta el punto en que sus privilegios sean otorgados en forma proporcional a la urgencia que haya en lo relativo a su intervención. En caso de guerra internacional o civil, en caso de recrudecimiento de la violencia en el país, estos privilegios tendrán que ser mayores que los otorgados en casos normales. Si no aumentan proporcionalmente, habrá un conflicto que podrá culminar en un golpe militar. Con todo, aun en este caso, el único canal que se rompería, por lo menos a corto plazo, sería el canal político. Si ese poder político se emplea en contra de los intereses de la minoría económica, ésta urdirá todas las maquinaciones necesarias para que caiga. Ya hemos resaltado la importancia de la fuerza económica sobre la política.

De esta suerte vemos cómo el canal militar está controlado por la minoría económica, política y cultural, que también controla el poder burocrático.

Sin embargo, es necesario anotar algunos rasgos de independencia del canal militar respecto de los canales económico y cultural. Aunque existe una valla cuasi infranqueable entre los grados de suboficiales y de oficiales por motivos económicos y sociales, más que por criterio de calificación funcional, la educación militar superior (para los oficiales) presenta algunas grietas para el ascenso social, a través de las oclusiones económicas y culturales.

La educación militar es bastante barata en relación con la educación privada en general. Además, hay una remuneración simultánea que ayuda eficazmente a descartar el freno económico. Estas facilidades producen un ascenso social de las clases bajas, inclusive hasta la clase media, con criterios que escapan relativamente a la estructura general económica y cultural. A esta última, por lo menos a partir de la educación secundaria.

Sin embargo, aunque por este canal, en forma excepcional hay más posibilidad de ascenso, el control de las minorías dominantes no se descarta. Por el contrario, a todas las escalas, hay una exigencia que culmina en el "conformismo contractual" de que tratamos arriba en lo más alto de la jerarquía militar.

La violencia tuvo varios efectos respecto de la estructura del ejército colombiano. 
Sin embargo, aquí consideramos los efectos que tuvo sobre la sociedad campesina como ganadora de un canal militar informal de ascenso social. En este aspecto tenemos que los efectos más importantes para el cambio socio-cultural fueron:

La creación de un ejército informal.

Los criterios nuevos que rigen los ascensos dentro de este nuevo ejército.

a) Creación de un ejército informal

Como lo referimos al hablar del canal administrativo, el ejército guerrillero tuvo una estructura bien establecida, copiada de la estructura del ejército regular, mezclada con una estructura administrativa informal y adaptada a las necesidades de la "guerra de guerrillas". Además de los grados tradicionales existieron otras funciones que permitieron el enrolamiento de mujeres y niños. ${ }^{27}$

b) Criterios nuevos que rigen los ascensos dentro de este ejército

A pesar de que en toda institución militar el conformismo a los superiores es un criterio básico para el ascenso, es necesario analizar si la institución militar misma es una institución conformista respecto de las estructuras vigentes.

Como analizamos antes, el ejército en un país subdesarrollado tiene como primordial función mantener el orden interno, lo que traducido al campo político significa mantener las estructuras vigentes. El ejército guerrillero tiene un objeto precisamente contrario: transformar esas estructuras. Por esto, los criterios de ascenso deben ajustarse a la eficacia revolucionaria del ascendido.

Además de esos criterios básicos tenemos algunos otros como el de lealtad, el grado de crueldad, la valentía, el espíritu de servicio, etc. ${ }^{28}$ Con todo, es necesario anotar

${ }^{27}$ Cfr. La violencia en Colombia, op cit., p. 163-164.

${ }^{28}$ La violencia en Colombia, op cit., pp. 158-159. Mandamientos del Buen Guerrillero y Condiciones para 
algunos criterios intelectuales y políticos que se han tenido en cuenta en las guerrillas para efectuar los ascensos, y además la estructura más democrática, por el contrario, entre los superiores e inferiores y por la institucionalización de la crítica y de la emisión de opiniones por parte de los inferiores.

Los campesinos encontraron un canal de ascenso social dentro del ejército informal que no hubieran hallado nunca dentro del ejército regular de nuestro país.

Jefes guerrilleros, a cuya extracción social nos referimos antes, difícilmente hubieran podido llegar a tener los títulos que hoy ostentan, tales como el de general, coronel, capitán, etc.

En la primera edición del libro La violencia en Colombia, encontramos retratos como el de "Mariachi" vestido de uniforme de general, pasando revista a sus tropas. Es muy poco probable que Mariachi hubiera llegado siquiera al grado de oficial dentro del ejército regular, y si lo hubiese hecho habría sido adaptándose a los criterios de conformismo con las estructuras vigentes y con el necesario apoyo económico y político de las clases dirigentes para llegar a los últimos grados.

La violencia abrió en esta forma otro canal de ascenso social. En éste, como en el caso de los canales anteriormente analizados, podemos afirmar que la necesidad de ascenso se crea por vías anómicas o patológicas cuando es imposible realizarla por vías normales.

No podemos afirmar que la creación de un auténtico ascenso masivo y popular por el canal militar sea la solución para evitar la creación de estos ejércitos informales. Como lo repetiremos en la conclusión, lo importante es ver la necesidad general de ascenso que, cuando se ve obstruida por las vías normales, busca vías anormales, sin que la clase de canal sea muy importante para realizar ese ascenso.

Respecto del cambio social, es necesario anotar que las estructuras mismas de ese ejército informal cambiaron los valores, las actitudes y la conducta, no solamente de los campesinos que en el ejército han participado, sino de los campesinos que han tenido 
contacto con ese ejército.

Las guerrillas han impuesto disciplinas exigidas por los mismos campesinos: han democratizado la autoridad, han dado confianza y seguridad a nuestras comunidades rurales, como lo mencionamos al tratar del espíritu de inferioridad, desaparecido en las áreas campesinas en donde el fenómeno de la violencia se ha manifestado. Todas estas transformaciones socio-culturales en el campesinado lo disponen a ser un grupo de presión para un cambio general de estructuras, como analizaremos más adelante. 


\section{Canal eclesiástico}

El canal eclesiástico de ascenso social está constituido, en los países subdesarrollados de Latinoamérica, por los diferentes grados y dignidades establecidos por la iglesia Católica. Dada la poca importancia social institucional de los otros canales dependientes de una institución religiosa, no los tomaremos por ahora en cuenta. Por otra parte, es necesario distinguir entre los grados oficiales y aquellos que atañen a la escala social propiamente dicha.

Dentro de ésta podemos establecer los grados de seminarista, coadjutor o capellán, párroco rural, párroco urbano de barrio obrero, de barrio residencial, monseñor o canónigo, obispo auxiliar, obispo principal, arzobispo y cardenal.

Dentro de cada una de las anteriores categorías puede haber una oscilación de estatus bastante considerable. Sin embargo, como clasificación tentativa proponemos la siguiente como promedio para cada estrato:

Seminarista. Clase media baja.

Coadjutor o Capellán. Clase media media.

Párroco rural. Clase media media.

Párroco urbano (obrero). Clase media media.

Párroco urbano (barrio residencial). Clase media alta.

Monseñor o Canónigo. Clase alta baja.

Obispo auxiliar. Clase alta media.

Obispo principal. Clase alta media.

Arzobispo. Clase alta media.

Cardenal. Clase alta media o alta, según la extracción familiar.

Aunque la clasificación anterior (como toda clasificación, más aún en sociología y 
con el agravante de no estar fundamentada sino en la observación participante), pueda resultar un poco arbitraria, lo que tratamos de afirmar fundamentalmente es que el canal eclesiástico es un canal muy efectivo de movilidad social ascendente. Esto se hace aún más notorio si consideramos que la mayoría (en términos absolutos) de los eclesiásticos son de extracción rural. Sin embargo, la clase social rural de origen es más bien clase media media (comerciantes, pequeños hacendados, maestros, etc.) ${ }^{29}$, lo que no significa un paso de ascenso al comienzo del canal eclesiástico. Una de las particularidades de éste es su relativa independencia del canal económico. Creemos que no erramos al afirmar que es el canal que tiene una mayor independencia de las minorías económicas, por las siguientes razones:

Las bajas pensiones de los seminarios, tanto menores como mayores.

El número de becarios, generalmente superior al de los pensionados.

En este último factor influye en alguna medida el nivel económico, por cuanto los candidatos preferidos para las becas son los que tienen un nivel social de origen superior. Este nivel social está estrechamente ligado al nivel económico y cultural, como lo describimos atrás.

El canal de ascenso, en su primera etapa (el seminario) tiene un carácter predominantemente cultural formal. Ese ascenso se efectúa generalmente desde la escuela primaria (escuela apostólica) hasta la escala universitaria (seminario Mayor).

Los criterios de ascenso en esta etapa son predominantemente los de capacidad intelectual y conformismo en la conducta ${ }^{30}$.

En las etapas siguientes, el criterio primordial de ascenso en la estructura actual de la iglesia latinoamericana es el conformismo. Por ejemplo, en algunos países los obispos no son elegidos sin la aceptación del candidato por todo el episcopado nacional. Esto implica una nivelación del candidato sobre la base del conformismo, principalmente.

Creemos que el canal eclesiástico no es más utilizado como canal de ascenso social, en

${ }^{29}$ Cfr. Gustavo Pérez, El problema sacerdotal en Colombia, Editorial Rivadeneira, Madrid, 1962.

30 Aunque formalmente se habla de "virtud" en el sentido de "autodominio" en la práctica, como promedio, se trata de "conformismo". 
los países latinoamericanos, por dos razones fundamentales:

La lentitud de ascenso en la primera etapa (6 a 7 años de seminario mayor).

La alta mortalidad educacional (en Colombia más o menos el 50\% de los ingresados al primer año de Seminario Mayor).

Estos frenos hacen que se necesite un grado alto de conformismo y de madurez intelectual y emocional en la familia de origen o en el individuo (si se trata de un candidato adulto).

El ingresar a un seminario supone una serie de patrones culturales (deseo de cambio, de progreso, de liderazgo), que se deben realizar a largo plazo. Estos patrones, como promedio, no se encuentran en la clase baja. Se necesita partir de la clase media baja o clase media en general.

De todas maneras, podemos concluir que el canal eclesiástico de ascenso social es un canal eficaz, con oclusiones más culturales que económicas, políticas o burocráticas.

Sin embargo, es necesario medir el alcance de las oclusiones culturales; las exigencias de competencia intelectual son exigencias objetivas, aunque siempre limitadas por el género de exigencia que se haga. Si la prueba se hace basándose en un sistema no apto para las necesidades actuales, triunfar en ella no es tan significativo de eficiencia, como si se trata de un sistema apto.

Las exigencias de conformismo pueden crear, en un país subdesarrollado, una movilidad social material y no socio-cultural. En otras palabras, puede ser que un individuo de clase media baja, o aun de clase baja, llegue a ser arzobispo o cardenal. Sin embargo, es fácil que solamente se le tolere en ese cargo a costa de un conformismo absoluto con los valores de la minoría dominante. Entonces tendríamos que el canal eclesiástico de ascenso social resultaría ser más material que socio-cultural. Esto se agrava en aquellos países en que tiene una injerencia formal o informal el poder político sobre los nombramientos de los obispos y sobre la pastoral general de la iglesia.

No es que en los países desarrollados el cambio de clase no implique un cambio de valores; sin embargo, no es la condición sine qua non del cambio como parece serlo en el canal eclesiástico. 
Obviamente, el análisis anterior es bastante simplista. Los factores económicos, familiares, políticos, culturales y burocráticos inciden en diversos grados y en diferentes composiciones con el canal eclesiástico de ascenso. Sin embargo, quisimos únicamente destacar los rasgos que parecen principales.

Actualmente la presión popular influye poco en el ascenso por el canal eclesiástico. Es cierto que la aceptación del sacerdote en una determinada comunidad o el rechazo por parte de ésta tiene alguna influencia para el ascenso. Sin embargo, es necesario anotar que antes del fenómeno de la violencia la aceptación o rechazo que eran tenidos en cuenta para el ascenso o descenso social no era la de la mayoría de la comunidad sino, fundamentalmente, la de los líderes tradicionales o burocráticos de ésta. es fácil que un sacerdote popular entre la mayoría de sus fieles sea trasladado por la presión de una minoría influyente.

Este fenómeno se produjo especialmente porque la mayoría del campesinado no constituía un grupo de presión y porque su actitud respecto del sacerdote, especialmente en las áreas rurales, era pasiva y carente de crítica.

Naturalmente que la unión de intereses entre la alta jerarquía y la clase dirigente produce que los ascensos eclesiásticos tengan como uno de los criterios básicos el conformismo con las estructuras, que se manifiesta en la escala local en el conformismo con los grupos minoritarios dirigentes de las comunidades de base.

Durante la violencia asistimos a la muerte de varios sacerdotes ${ }^{31}$, a profanaciones y a actos iconoclastas, lo cual revela un cambio en la actitud del campesinado respecto de la institución eclesiástica.

Es muy posible que la desafección del campesino a esta institución no sea producida solamente por aquellos elementos del clero que estimularon en alguna forma las matanzas de campesinos. Sería interesante hacer un estudio sistemático sobre las actitudes religiosas del campesinado colombiano en las áreas de violencia.

Sin embargo, como hipótesis de trabajo, podemos decir que el campesinado

${ }^{31}$ Cfr. La violencia en Colombia, op cit., p. 171. 
colombiano tuvo una actitud de rechazo al sacerdote en esas áreas en donde no encontró esa solidaridad franca por parte de éstos respecto de los intereses campesinos.

Es muy posible que los criterios de popularidad del sacerdote en las comunidades rurales hayan cambiado. Y no basta que éste sea un buen administrador o que no haga nada malo. Es necesario que el campesino lo sienta solidario con sus intereses.

En el caso de que la mayoría del campesinado se constituya en grupo de presión, es muy posible que a largo plazo los criterios de ascenso por el canal eclesiástico hayan cambiado. Sin embargo, para un cambio fundamental en los criterios de ascenso, es necesario que los criterios de la alta jerarquía no estén necesariamente ligados a los criterios e intereses de las clases dirigentes y, por lo tanto, al mantenimiento de las estructuras actuales.

Si el grupo de presión campesino, además de llegar a ser el más efectivo por la expresión de su aprobación o rechazo del sacerdote, llegara a producir un divorcio entre los intereses de la clase dirigente y los intereses de la iglesia, cambiaría fundamentalmente la estructura del ascenso social por el canal eclesiástico, imponiendo para el ascenso social criterios basados en los intereses campesinos en lugar de los criterios basados en los intereses de la clase dirigente.

A nadie escapa la trascendencia que para el cambio social tiene, en un país como Colombia en el cual la institución religiosa tiene aún mucha influencia, el hecho de que los dirigentes eclesiásticos tengan una actitud de cambio basada en los intereses de la mayoría.

Como conclusión general podemos afirmar:

1ำ Que en los países subdesarrollados, en los latinoamericanos y en Colombia en particular, los canales de movilidad social ascendente están estructuralmente obstruidos para la mayoría de la población.

$2^{\text {}}$ Que el factor que condiciona en forma más determinante la oclusión y el control de los demás canales es el económico.

3ํㅜㄹ la minoría de la población que controla la movilidad social ascendente está interesada en mantener la obstrucción de los canales de ascenso y por eso el conformismo es una condición indispensable para que ésta se efectúe. 
4ํQue la movilidad social ascendente es más de tipo minoritario que masivo, más material que sociocultural y, por tanto, sin efectos a corto plazo sobre el cambio social.

5ํ Que esta inmovilidad se presenta en forma más aguda en las áreas rurales de dichos países.

60 Que la violencia simultáneamente produjo una conciencia de clase y dio instrumentos anormales de ascenso social.

7으 Que las estructuras del ascenso anormal establecidas por la violencia cambiaron las actitudes del campesinado colombiano, transformando el campesinado en un grupo mayoritario de presión.

b) Agresividad latente

La agresividad puede ser individual o social. La agresividad individual es el resultado de un deseo de destrucción originado en una frustración. La destrucción se busca como una compensación y como un medio de reconstrucción de lo que no se ha logrado.

La agresividad social tiene las mismas características pero extendidas al grupo social. La agresividad puede ser manifiesta o latente, según el deseo de destrucción se pueda realizar o no.

La agresividad social en general se encuentra en aquellos países en los cuales hay frustración de aspiraciones, Si esa frustración de aspiraciones forma parte de la conciencia social y dentro de las instituciones sociales encontramos instrumentos violentos y eficaces de realización ${ }^{32}$, la agresividad se hará manifiesta.

Según lo expuesto anteriormente, en las áreas rurales de los países en desarrollo encontramos una gran inmovilidad social ascendente que produciría una frustración de

32 “Realización” en el sentido que explica T. Parsons de "performance” (Cfr. T. Parsons, t. Bales, r. F. and shils. e. A., "Working papers in the theory of Action", 1953, Cp. v. sec., v; Parsons y N. J. Smelser, Economy and society, routledge and Kegan, paul, londres, 1956. 
aspiraciones en el caso de que haya conciencia de ella. Esa conciencia se adquiere por un cambio social inducido. Cuando las comunicaciones humanas se extienden y aumentan, la conciencia social aumenta y si se conocen puntos de comparación, las frustraciones aparecen.

Ahora bien, si existe la conciencia pero no se conocen los instrumentos institucionales de realización, la agresividad seguirá en su estado latente.

Si los instrumentos institucionales eficaces se conocen y esos instrumentos están dentro de las estructuras vigentes, la agresividad latente se resolverá en una acción institucional que no violente las estructuras. Si, por el contrario, los instrumentos institucionales que se conocen están contra las estructuras vigentes, la agresividad latente se convertirá en agresividad manifiesta. Esta agresividad manifiesta se hará tanto más intensa cuanto más conciencia haya de las frustraciones y cuanto por un lado sean más eficaces los instrumentos contra las estructuras y, por otro, menos eficaces los instrumentos de acuerdo con éstas.

En las áreas rurales de los países latinoamericanos encontramos los diferentes grados de frustración y de conciencia y las diferentes combinaciones de instrumentos normales y anormales (de acuerdo o no con las estructuras). En todo caso la falta de movilidad social en estas áreas es un elemento de agresividad latente.

En Colombia la agresividad social latente se ha vuelto manifiesta en forma intermitente a todo lo largo de su historia. Desde las guerras precolombinas entre los indígenas, pasando por las luchas de la Con- quista, las revueltas de la época colonial, la guerra de independencia, las guerras civiles posteriores a ésta y las manifestaciones de violencia que se ha solido llamar política (como la del año 1930) hasta el fenómeno de violencia actual que hemos definido tentativamente al principio de este estudio.

Ya se ha visto, al considerar las variables anteriores, cómo la violencia introdujo simultáneamente:

La conciencia de la frustración.

La agudización de la frustración.

Los instrumentos eficaces, pero anormales, para resolver la frustración. 
La acción armada de las fuerzas oficiales fue el elemento de cambio social inducido por el cual se produjeron los tres efectos anteriores.

Podemos por lo tanto afirmar que el fenómeno común a las áreas rurales subdesarrolladas descrito como agresividad latente se ha expresado en nuestras comunidades campesinas haciéndose agresividad manifiesta en el fenómeno de la violencia.

\section{3ํVaiables características de la sociedad Rural colombiana}

a) Sectarismo político

Lo que se ha solido llamar "sectarismo político" es una forma de agresividad de grupo y, en concreto, de un grupo que forma parte de una organización que ejerce o pretende el poder estatal. Además del elemento de agresividad, debemos incluir en la expresión "sectarismo político" las nociones correlativas de seguridad intra-grupo e inseguridad extra-grupo.

Toda pertenencia a un grupo es un efecto y una causa a la vez de la necesidad de seguridad social que tiene todo individuo. Esa función de seguridad que da el grupo, será tanto más intensa cuanto mayor sea la inseguridad de permanencia fuera del grupo. En los países desarrollados, además, existen instituciones que garantizan la seguridad social en forma independiente de la pertenencia a un grupo. Por esto, la necesidad de pertenencia a grupos es mucho menor en estos países que en los nuestros. Como por otra parte la agresividad social es mayor en el país subdesarrollado porque las frustraciones son en general mayores, podemos afirmar que el sectarismo político es un subproducto de la falta de desarrollo socioeconómico.

En los países no industrializados la pequeña minoría que detenta el poder constituye un grupo en sí bastante cerrado, como vimos antes, y que tiene la mayor cuota de seguridad dentro de la sociedad. La única forma de perder esta seguridad sería el cambio de estructuras que acarreará la pérdida del control social.

Evidentemente, dicho cambio no podrá provenir sino del extra-grupo, es decir, de la mayoría de la población que no puede ascender. Con todo, el hecho mismo de ser una minoría constituye un elemento de inseguridad en el caso de que la mayoría se muestre 
descontenta. Por consiguiente, es necesario algún mecanismo que satisfaga a la mayoría, mantenga las estructuras y, si es posible, haga peligroso cualquier cambio de éstas.

El partido político puede cumplir con las funciones anteriores, siempre y cuando llene determinados requisitos: en primer lugar, debe dar algunas satisfacciones suficientes para evitar el descontento. En segundo lugar, debe relacionar las satisfacciones de necesidades al mantenimiento de las estructuras, y en tercer lugar debe crear sistemas para hacer peligroso el cambio de éstas.

El partido político en Colombia es un instrumento para la satisfacción de algunas necesidades de la mayoría de los colombianos. Dada la importancia del botín burocrático en un país subdesarrollado (con mano de obra poco calificada, alto porcentaje de ingreso nacional dedicado a la administración y pocas exigencias técnicas por parte de ésta), el partido político es una importante fuente no solamente de subsistencia de muchos colombianos ya que de él depende la repartición de este botín. En otras palabras, muchos más dependen de los empleos públicos, aunque no los ejerzan, por la expectativa que tienen de ejercerlos. Por lo tanto, son muchos los colombianos que dependen directa o indirectamente del partido político.

Sin embargo, para que esa dependencia implique a la vez una garantía para el mantenimiento de las estructuras socioeconómicas, es necesario que exija una dependencia a la clase dirigente. Por esta razón, para que el partido sea un instrumento apto de conservación para esta clase, debe ser poli-clasista, es decir, debe estar estructurado en base a la pertenencia de todas las necesidades sociales a esa clase dirigente. Como es lógico, si la pertenencia no trae ventajas técnicas ni racionales es necesario buscar motivaciones sentimentales que la justifiquen. De allí la base tradicional o sentimental que tienen los sistemas de partido, ya que el botín burocrático, que de hecho es re- partido por la clase dirigente, podría ser administrado por la mayoría de la población en forma más técnica y racional.

Para que este mantenimiento de las estructuras sea sólido y duradero, es necesario que su rompimiento entrañe un peligro para la clase que no se beneficia con el sistema vigente. El sectarismo político es el instrumento por el cual la clase dirigente logra que esa mayoría encuentre una seguridad intra-grupo, proporcional a una inseguridad extragrupo. 
En resumen, el partido político tiene funciones respecto tanto de la clase dirigente como de la mayoría de los dirigidos; para la clase dirigente constituye un elemento de conservación de las estructuras por el sentimentalismo partidista y por el sectarismo político, y no permitiendo la reestructuración de los partidos sobre bases racionales que transformen las estructuras implantando el gobierno de las mayorías.

Para la clase dirigida el ambiente social de inseguridad que produce el sectarismo político, el partido constituye un grupo de refugio y el único capaz de relacionarlo con la clase dirigente, es decir, con la fuente de su propia seguridad. Esta relación debe establecerse con la condición indispensable del conformismo respecto del propio partido. Conformismo que se demuestra y se afianza más con manifestaciones de sectarismo contra el partido contrario. El sectarismo político es pues el instrumento de doble filo que refuerza el conformismo de la clase dirigida y garantiza la estabilidad de las estructuras a la clase dirigente.

La violencia fue desatada como un instrumento del sectarismo para que cumpliera las funciones que hemos atribuido a éste. De ahí que la violencia no se produjo entre las clases dirigentes, sino entre la masa de los campesinos sentimentalmente divididos en los partidos tradicionales, padeciendo una mayor inseguridad social, que los aferraba aún más a esos partidos. Por eso también una vez hecha la unión política entre las clases dirigentes, la violencia ha continuado para garantizar el sectarismo necesario que impide la reestructuración de los partidos sobre bases racionales capaces de transformar las estructuras. Dentro de esta política es lógico que cualquier individuo que se arriesgue a disentir de las directivas y de los partidos tradicionales, sea considerado como marginal y casi como fuera de la ley. Es sintomática la aparición de las sociedades macartistas, compuestas por elementos de la clase dirigente de ambos partidos. La función formal de estas sociedades es la de perseguir al comunismo y la función informal es la de marginar a todo individuo o movimiento anticonformista que aparezca en el escenario político, social o económico. La violencia, por lo tanto, no favorece a uno u otro partido político en particular; en ocasiones, puede favorecer más a un partido minoritario nivelando con el terror las fuerzas políticas desniveladas por diferencias electorales. Sin embargo, la violencia favorece fundamentalmente a toda la clase dirigente de cualquier partido que ésta sea. 
A pesar de todo, la violencia ha desencadenado un proceso social imprevisto por las clases dirigentes. Ha despertado la conciencia del campesino, le ha dado solidaridad de grupo, sentimiento de superioridad y seguridad en la acción; ha abierto posibilidades de ascenso social, y ha institucionalizado la agresividad, haciendo que los campesinos colombianos comiencen a preferir los intereses del campesinado a los intereses del partido. Esto tendrá como efecto la constitución de un grupo de presión social, económica y aun política capaz de cambiar las estructuras en la forma menos prevista y menos deseada por la clase dirigente. Es muy posible que, debido a la violencia, el sectarismo político se cambie por sectarismo de clase como se ha visto en muchas áreas rurales colombianas.

b) Falta de conciencia de clase

Escapa a los fines del presente análisis entrar en disquisiciones sobre la definición de clase social. Para nuestros objetivos basta tener una definición generalmente aceptada. Cuando hablamos de la clase campesina nos referimos a un cierto grupo social del estatus económico más bajo dentro de la sociedad colombiana. Consagrado a una ocupación dentro del sector primario de la producción, localizado predominantemente en las áreas rurales del país. Conciencia de clase es la que existe respecto de una serie de relaciones sociales existentes dentro del grupo antes definido, relaciones de tipo exclusivo respecto del extra-grupo. Cuando esta conciencia de clase se une a la iniciativa en (y a la) organización para la acción del grupo que la posee, es capaz de influir en las decisiones gubernamentales y, por lo tanto, es capaz de volverse un grupo de presión.

En muchos países subdesarrollados el campesinado se ha organizado en diversas formas. Los movimientos agrarios en Latinoamérica han tenido una importancia que contrasta con la que han tenido en nuestro país.

El carácter más pronunciado de las variables arriba señaladas, especialmente la del individualismo y la del aislamiento, han hecho que el campesinado colombiano no haya tenido una conciencia de clase. Por otra parte el aislamiento cultural de nuestro país, junto con el atraso en el equipo técnico de comunicaciones, han impedido las interacciones 
culturales necesarias para un cambio social capaz de crear una conciencia de clase. La ausencia de contactos ha producido una falta de conciencia sobre las propias necesidades, por falta de conocimiento de otros grupos de referencia. La falta de movilidad social ascendente ha tenido por efecto la institucionalización de un fatalismo respecto de la solución de algunas pocas necesidades sobre las cuales hay conciencia. Aun en el caso en que, por alguna circunstancia, haya conciencia de las necesidades y el fatalismo haya sido reemplazado por una actitud de iniciativa en la acción, generalmente esto ha sucedido a escala individual. Los conflictos con los extra-grupos campesinos han impedido la creación de una solidaridad rural, y el sectarismo político ha agudizado la desunión.

Aun después de la aparición de la violencia, podemos observar las comunidades rurales que no han sufrido el influjo de ésta ni directa ni indirectamente y encontramos las características de conciencia respecto de las necesidades, fatalismo ante el progreso y falta de seguridad colectiva entre los campesinos.

Al considerar los efectos de la violencia sobre la creación de la conciencia de clases en el campesinado colombiano, podemos recapitular el análisis sobre los cambios acaecidos de las otras variables:

La demasiada importancia del vecindario local, el aislamiento, el individualismo, los conflictos intra y extra-grupo, el sentimiento de inferioridad, la ausencia de movilidad social vertical ascendente, la agresividad latente, implican una falta de conciencia de clase. La violencia, al alterar las anteriores variables, comienza a crear una conciencia de clase; generaliza las relaciones sociales entre los campesinos de casi todo el país, da conciencia de que esas relaciones son exclusivas del grupo campesino, y además da solidaridad para la acción comenzando a influir informalmente en las decisiones gubernamentales y por medio de pactos políticos en las estructuras vigentes. De la falta de esa conciencia de clase, el campesino está pasando paulatinamente a ser un grupo de presión que será definitivo en el cambio social de las estructuras colombianas. 
c) Respecto a la propiedad privada

De los diversos informes de los Cronistas de indias, los historiado- res de la colonia y de los historiadores latinoamericanos, podemos concluir que la forma de propiedad más generalizada dentro de las comunidades indígenas era la forma de posesión colectiva de la tierra. La obra colonizadora española no afectó decisivamente la mentalidad indígena respecto de la propiedad. Las organizaciones rurales colectivas continuaron bajo nuevos patrones eclesiásticos, militares o civiles ${ }^{33}$.

Con el movimiento emancipador se introdujeron las ideas liberales, dentro de las cuales la idea de la propiedad privada como base de la estructura política y social colombiana. el respeto a la propiedad privada pasó a ser patrimonio de los valores culturales colombianos. Antes de la violencia, nuestro campesinado tenía un respeto formal a la propiedad privada, respeto que informalmente era desconocido en algunas ocasiones por la conducta de éste. Durante la violencia se introdujo la institución del jus primo possidenti ${ }^{34}$.

Las expropiaciones ejercidas a menor precio, las invasiones, el control sobre cosechas y mercadeo, ejercidas por los grupos guerrilleros, hicieron perder a nuestros campesinos ese valor cultural que habían adquirido en el último ciclo.

En las comunidades en donde surgió este fenómeno se han organizado invasiones de tierras, con una facilidad que no solamente puede ser explicada por la presión económica, sino que tiene como base la práctica, durante la violencia, de hacer uso de la propiedad ajena para los fines inmediatos de subsistencia. Aunque este efecto de la violencia es accesorio y aparentemente intrascendente, es importante respecto del cambio social; si, como vimos antes, el campesinado se está constituyendo paulatinamente en un grupo de presión, es importante conocer los patrones culturales de ese grupo. Si el respeto de la propiedad privada ha dejado de ser un elemento dentro de

${ }^{33}$ Como estudios sobre la evolución del concepto de la propiedad en Colombia, consúltese Alfonso López Michelsen, Introducción al estudio de la Constitución de Colombia.

${ }^{34}$ La violencia en Colombia, op cit. 
esos patrones, es muy posible que en el cambio de estructuras que pueda llevar a cabo la presión de este grupo se ataque directamente la estructura de la propiedad.

\section{Conclusión}

Basados en el análisis anterior, podemos decir que la violencia ha constituido para Colombia el cambio socio-cultural más importante en las áreas campesinas desde la conquista efectuada por los españoles. Por conducto de ellas las comunidades rurales se han integrado dentro de un proceso de urbanización en el sentido sociológico, con todos los elementos que éste implica: la división del trabajo, especialización, contacto sociocultural, socialización, mentalidad de cambio, despertar de expectaciones sociales y utilización de métodos de acción para realizar una movilidad social por canales no previstos por las estructuras vigentes. La violencia además ha establecido los sistemas necesarios para la estructuración de una subcultura rural, de una clase campesina y de un grupo de presión constituido por esta misma clase, de carácter revolucionario. Sin embargo, la violencia ha opera- do todos estos cambios por canales patológicos y sin ninguna armonía respecto del proceso de desarrollo económico del país.

Aunque es muy difícil predecir, es muy poco probable que haya cambios estructurales lo suficientemente profundos, realizados por la sola iniciativa de la clase dirigente actual, para encauzar todas esas fuerzas anómicas dentro de un proceso de desarrollo planificado técnicamente. Sin embargo, la orientación hacia los problemas agrarios que han tenido los últimos gobiernos podría producir el efecto de la creación de un liderazgo de base capaz de dirigir las presiones del campesinado hacia objetivos de desarrollo social y económico. Si estas presiones se ejercen en forma suficientemente técnicas y enérgicas, podrían cambiar la estructura de nuestra clase dirigente, siempre y cuando ésta sea capaz de valorar a tiempo el peligro de una transformación que la destruya completamente, por no haber podido adaptarse a un cambio social que se presenta como inevitable.

\section{Referencias}


ASOCIACIÓN COLOMBIANA DE UNIVERSIDADES (1961). Estadística de la Educación Superior. Bogotá.

DURKHEIM, Émile. (1902) De la división du Travail Social, XXXII.

FALS BORDA, Orlando. (1961) Campesinos de los Andes, Editorial Iquelma: Bogotá.

FALS BORDA, Orlando. (1956) El hombre y la tierra en Boyacá, Editorial Antares: Bogotá.

GUZMÁN, Germán; UMAÑA LUNA, Eduardo y FALS BORDA, Orlando. (1962). La violencia en Colombia, edición monografía sociológica, Facultad de sociología, U.N. Bogotá.

HANDLIN. Clases sociales en América latina. Ciencias sociales. Unión panamericana: Washington, D. C.

HUGHES, C. (1928) Personality Types and the Division of Labor. American Journal of sociology.

LÓPEZ MICHELSEN, Alfonso. (1945) Introducción al estudio de la Constitución de Colombia.

PARSONS y N. J. Smelser, (1956) Economy and society, Routledge and Kegan, paul: Londres.

PARSONS, T; BALES, r. F. and Shils. e. A., (1953) Working papers in the theory of Action. PÉREZ, Gustavo. (1962) El campesino colombiano, un problema de estructura, Centro de investigaciones sociales, Bogotá.

PÉREZ, Gustavo. (1962) El problema sacerdotal en Colombia, Editorial Rivadeneira: Madrid.

REDFIELD, Robert. (1947) The Folk Society. The American Journal of sociology, No 52. VON WIESE, Leopold and BECKER, Howard. (1932) Systematic Sociology. Nueva York: John Wiley \& Sons.

WEBER, Max (1944) Economía y sociedad. Fondo de Cultura económica de México. 